\title{
Manipulative interventions for reducing pulled elbow in young children (Review)
}

Krul M, van der Wouden JC, Kruithof EJ, van Suijlekom-Smit LWA, Koes BW

Krul M, van der Wouden JC, Kruithof EJ, van Suijlekom-Smit LWA, Koes BW.

Manipulative interventions for reducing pulled elbow in young children.

Cochrane Database of Systematic Reviews 2017, Issue 7. Art. No.: CD007759.

DOI: 10.1002/14651858.CD007759.pub4.

www.cochranelibrary.com 
TABLE OF CONTENTS

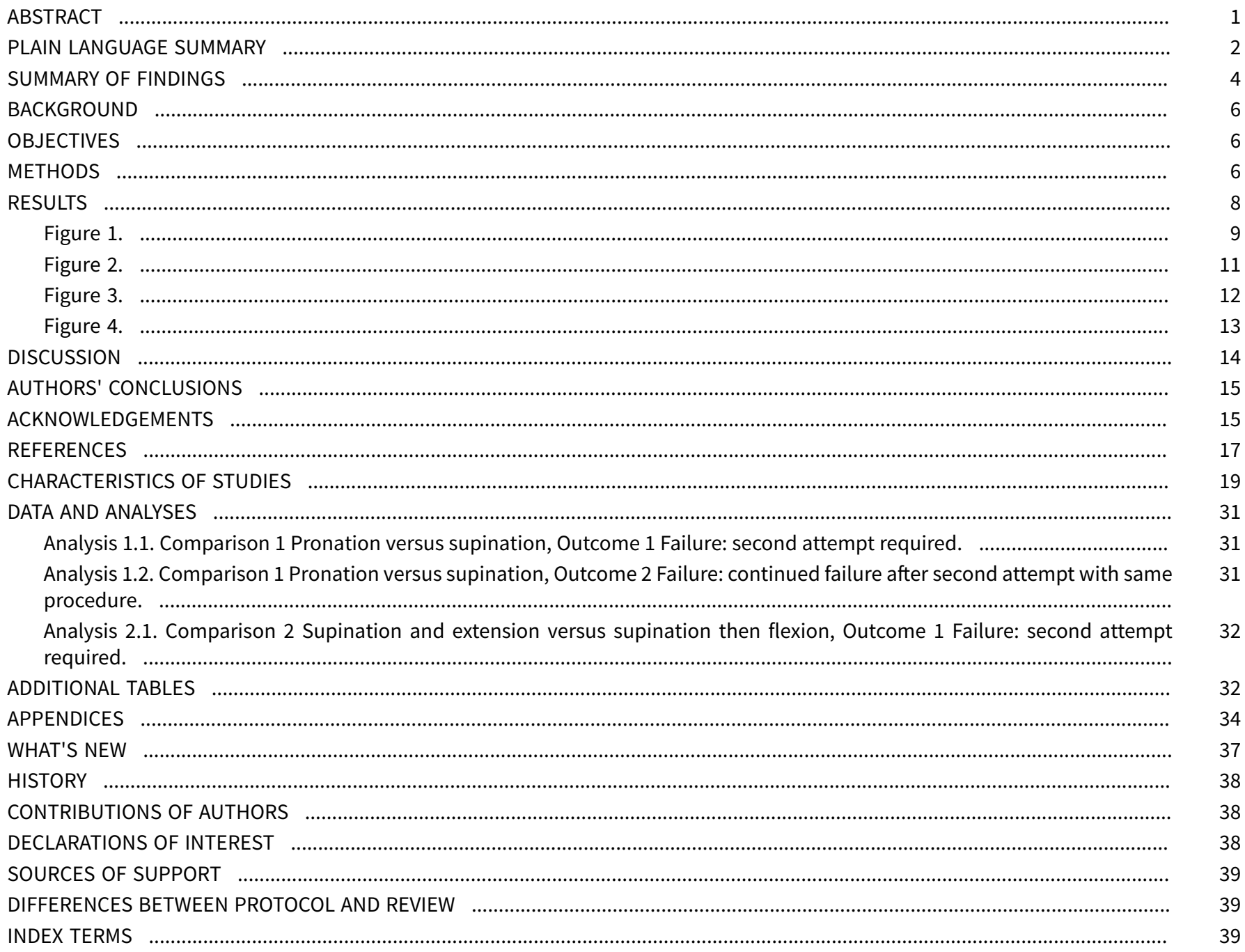


[Intervention Review]

\title{
Manipulative interventions for reducing pulled elbow in young children
}

\author{
Marjolein Krul1, Johannes C van der Wouden², Emma J Kruithof ${ }^{2}$, Lisette WA van Suijlekom-Smit ${ }^{3}$, Bart W Koes ${ }^{1}$ \\ 1Department of General Practice, Erasmus Medical Center, Rotterdam, Netherlands. 2Department of General Practice and Elderly \\ Care Medicine, Amsterdam Public Health Research Institute, VU University Medical Center, Amsterdam, Netherlands. ${ }^{3}$ Department of \\ Paediatrics, Paediatric Rheumatology, Erasmus Medical Center - Sophia Children's Hospital, Rotterdam, Netherlands
}

Contact: Johannes C van der Wouden, Department of General Practice and Elderly Care Medicine, Amsterdam Public Health Research Institute, VU University Medical Center, PO Box 7057, Amsterdam, 1007 MB, Netherlands. j.vanderwouden@vumc.nl.

Editorial group: Cochrane Bone, Joint and Muscle Trauma Group.

Publication status and date: New search for studies and content updated (conclusions changed), published in Issue 7, 2017.

Citation: Krul M, van der Wouden JC, Kruithof EJ, van Suijlekom-Smit LWA, Koes BW. Manipulative interventions for reducing pulled elbow in young children. Cochrane Database of Systematic Reviews 2017, Issue 7. Art. No.: CD007759. DOI: 10.1002/14651858.CD007759.pub4.

Copyright $\odot 2017$ The Cochrane Collaboration. Published by John Wiley \& Sons, Ltd.

\begin{abstract}
A B S T R A C T

\section{Background}

Pulled elbow (nursemaid's elbow) is a common injury in young children. It often results from a sudden pull on the arm, usually by an adult or taller person, which pulls the radius through the annular ligament, resulting in subluxation (partial dislocation) of the radial head. It can also be caused by a fall or twist. The child experiences sudden acute pain and loss of function in the affected arm. Pulled elbow is usually treated by manual reduction of the subluxed radial head. Various manoeuvres can be applied; most commonly, supination of the forearm, often combined with flexion, and (hyper-)pronation. It is unclear which is most successful. This is an update of a Cochrane review first published in 2009 and last updated in 2011.
\end{abstract}

\section{Objectives}

To compare the effects (benefits and harms) of the different methods used to manipulate pulled elbow in young children.

\section{Search methods}

We searched the Cochrane Bone, Joint and Muscle Trauma Group Specialised Register, the Cochrane Central Register of Controlled Trials, MEDLINE, Embase, CINAHL, LILACS, PEDro, clinical trial registers and reference lists of articles. Date of last search: September 2016.

\section{Selection criteria}

Randomised or quasi-randomised controlled clinical trials evaluating manipulative interventions for pulled elbow were included. Our primary outcome was failure at the first attempt, necessitating further treatment.

\section{Data collection and analysis}

Two review authors independently evaluated trials for inclusion, assessed risk of bias, and extracted data. We pooled data using a fixedeffect model.

\section{Main results}

Overall, nine trials with 906 children (all younger than seven years old and 58\% of whom were female) were included, of which five trials were newly identified in this update. Eight trials were performed in emergency departments or ambulatory care centres, and one was performed in a tertiary paediatric orthopaedic unit. Four trials were conducted in the USA, three in Turkey, one in Iran, and one in Spain. Five trials were at high risk of selection bias because allocation was not concealed and all trials were at high risk of detection bias due to the lack of assessor blinding. 
Eight trials compared hyperpronation with supination-flexion. We found low-quality evidence that hyperpronation resulted in less failure at first attempt than supination-flexion (9.2\% versus $26.4 \%$, risk ratio (RR) $0.35 ; 95 \%$ confidence interval $(\mathrm{Cl}) 0.25$ to $0.50 ; 811$ participants, 8 studies). Based on an illustrative risk of 268 failures at first attempt per 1000 children treated using supination-flexion, this amounted to 174 fewer failures per 1000 children treated using hyperpronation ( $95 \% \mathrm{Cl} 134$ to 201 fewer). Based on risk differences data, we also estimated a number needed to treat of $6(95 \% \mathrm{Cl} 5$ to 8$)$; this means that six children would need to be treated with the hyperpronation method rather than the supination-flexion method to avoid one additional failure at the first attempt.

The very low-quality evidence (from four studies) for pain during or after manipulation means that it is uncertain whether there is or is not a difference between pronation and supination-flexion. There was very low-quality evidence from six studies that repeat pronation may be more effective than repeat supination-flexion for the second attempt after initial failure. The remaining outcomes were either not reported (adverse effects, recurrence) or unsuitable for pooling (ultimate failure). Ultimate failure, reported for the overall population only because of the differences in the study protocols with respect to what to do after the first attempt failed, ranged from no ultimate failures in two studies to six failures ( $4.1 \%$ of 148 episodes) in one study.

One trial compared supination-extension versus supination-flexion. It provided very low-quality evidence (downgraded three levels for very serious risk of bias and serious imprecision) of no clear difference in failure at first attempt between the two methods.

\section{Authors' conclusions}

There was low-quality evidence from eight small trials that the pronation method may be more effective at first attempt than the supination method for manipulating pulled elbow in young children. For other outcomes, no conclusions could be drawn either because of very lowquality evidence or the outcomes not being reported. We suggest that a high-quality randomised clinical trial comparing hyperpronation and supination-flexion is required to provide definitive evidence. We recommend that this is preceded by a survey among clinicians to establish the extent of clinical equipoise and to optimise the study design and recruitment.

\section{PLAIN LANGUAGE SUMMARY}

\section{Different methods of manipulation for reducing pulled elbow in young children}

\section{What is pulled elbow?}

Pulled elbow is a dislocation of the elbow joint in a young child which is often caused by an adult, or taller person, suddenly pulling or tugging on the child's arm when it is straight, or when a child pulls away from an adult impulsively. It can also be caused by a fall or twist. The child immediately complains of pain and cannot use his or her arm.

\section{How is it treated?}

Treatment usually consists of manipulating the arm to get the bones of the elbow back into their correct position. It is usually treated by manual intervention. There are two typical manoeuvres, supination and pronation. In supination, the forearm is twisted or rotated outwards (palm of child's hand faces upwards), sometimes followed by bending of the elbow (flexion). While this is often used, it is not always successful. In pronation, the forearm is twisted or rotated inwards (palm of child's hand faces downwards). Both methods are generally safe, although bruising can occur and they can be painful.

\section{Results of the search}

We searched medical literature databases up to September 2016. We found nine small studies involving a total of 906 children, all of whom were younger than seven years old. Around six out of 10 children were girls. Eight studies were performed in emergency departments or ambulatory care centres. One study was performed in a specialist paediatric orthopaedic unit. Eight trials compared pronation versus supination. One compared two methods of supination.

\section{Key results}

The pronation method (with the hand downward) may be more successful in repositioning at first attempt for children with a pulled elbow. We estimated that if six children were treated with the pronation method rather than the supination method, this would avoid one more failure at the first attempt. The evidence was insufficient to draw any conclusions as to which, if either, of the two methods was more painful. Where there was a second attempt using the same method, pronation may be more successful as a second attempt. In a few cases, up to four in 100 , none of a series of attempts were successful. None of the studies reported on side effects or how many children had another pulled elbow subsequently (recurrence).

The study comparing two methods of supination provided very low-quality evidence that failure after the first attempt was similar in both methods.

\section{Quality of the evidence}


All nine studies had methodological limitations that may affect the reliability of their findings and put them at high risk of bias. The quality of the evidence for failure at first attempt in the pronation versus supination comparison was low, meaning that we are uncertain about the results. The very low quality of the evidence for the other outcomes for both comparisons means we are very uncertain about the results.

\section{Conclusions}

Low-quality evidence suggests that the pronation method is more successful than the supination method for reducing pulled elbow in young children. No conclusions can be drawn on other outcomes, including pain and side effects. 


\begin{tabular}{|c|c|c|c|c|c|c|c|}
\hline \multirow{13}{*}{ 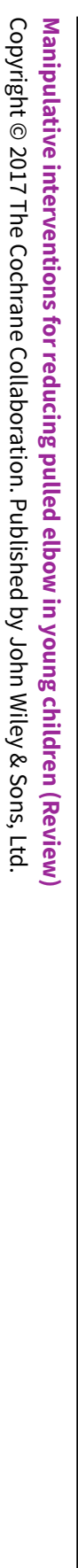 } & \multicolumn{7}{|c|}{$\begin{array}{l}\text { S U M M A R Y O F F I N D I N G S } \\
\text { Summary of findings for the main comparison. }\end{array}$} \\
\hline & \multicolumn{7}{|c|}{ Pronation compared with supination reduction techniques for pulled elbow in young children } \\
\hline & \multirow{4}{*}{\multicolumn{7}{|c|}{$\begin{array}{l}\text { Patient or population: Children with pulled elbow }{ }^{1} \\
\text { Settings: Emergency departments, ambulatory care centres or orthopaedic units } \\
\text { Intervention: Pronation (all were hyperpronation) for first manipulation } \\
\text { Comparison: Supination (all included flexion) for first manipulation }\end{array}$}} \\
\hline & & & & & & & \\
\hline & & & & & & & \\
\hline & & & & & & & \\
\hline & \multirow[t]{3}{*}{ Outcomes } & \multicolumn{2}{|c|}{$\begin{array}{l}\text { Illustrative comparative risks }{ }^{\star} \\
(95 \% \mathrm{Cl})\end{array}$} & \multirow[t]{3}{*}{$\begin{array}{l}\text { Relative effect } \\
(95 \% \mathrm{CI})\end{array}$} & \multirow{3}{*}{$\begin{array}{l}\text { No of Partici- } \\
\text { pants } \\
\text { (studies) }\end{array}$} & \multirow{3}{*}{$\begin{array}{l}\text { Quality of the } \\
\text { evidence } \\
\text { (GRADE) }\end{array}$} & \multirow[t]{3}{*}{ Comments } \\
\hline & & Assumed risk & $\begin{array}{l}\text { Corresponding } \\
\text { risk }\end{array}$ & & & & \\
\hline & & $\begin{array}{l}\text { Supina- } \\
\text { tion-flexion }\end{array}$ & $\begin{array}{l}\text { Hyperprona- } \\
\text { tion }\end{array}$ & & & & \\
\hline & $\begin{array}{l}\text { Failure: sec- } \\
\text { ond attempt } \\
\text { required }\end{array}$ & 268 per $1000^{2}$ & $\begin{array}{l}94 \text { per } 1000 \\
(67 \text { to } 134)\end{array}$ & $\begin{array}{l}\text { RR } 0.35 \\
(0.25 \text { to } 0.50)\end{array}$ & $\begin{array}{l}\mathbf{8 1 1} \\
\text { (8 studies) }\end{array}$ & $\begin{array}{l}\oplus \oplus \odot \odot \\
\operatorname{low}^{3}\end{array}$ & \\
\hline & $\begin{array}{l}\text { Pain (prefer- } \\
\text { ably during the } \\
\text { procedure) }\end{array}$ & see Comments & see Comments & & see Comments & $\begin{array}{l}\oplus \odot \odot \odot \\
\text { very low } 4\end{array}$ & $\begin{array}{l}\text { Data for this outcome are incomplete and were mea- } \\
\text { sured in very different ways in four studies. }\end{array}$ \\
\hline & $\begin{array}{l}\text { Adverse ef- } \\
\text { fects (e.g. } \\
\text { bruising) }\end{array}$ & see Comments & see Comments & & & & None of the trials reported this outcome. \\
\hline & $\begin{array}{l}\text { Failure: con- } \\
\text { tinued failure } \\
\text { after second } \\
\text { attempt using } \\
\text { same proce- } \\
\text { dure as before }\end{array}$ & 147 per $1000^{2}$ & $\begin{array}{l}24 \text { per } 1000 \\
(14 \text { to } 47)\end{array}$ & $\begin{array}{l}\text { RR } 0.16 \text { (0.09 to } \\
0.32)\end{array}$ & $\begin{array}{l}624 \\
\text { (6 studies) }\end{array}$ & $\begin{array}{l}\oplus \ominus \ominus \ominus \\
\text { very low } 5\end{array}$ & $\begin{array}{l}\text { This outcome represented the cumulative effect of two } \\
\text { manipulations using hyperpronation versus cumulative } \\
\text { effect of two manipulations using supination-flexion. } \\
\text { Reassuringly, both procedures when used again result- } \\
\text { ed in further successful reductions; these were propor- } \\
\text { tionally greater with hyperpronation ( } 64 \% \text { versus } 28 \% \text { ). } \\
\text { However, the second attempt should not be considered } \\
\text { independently of the first attempt and the characteris- } \\
\text { tics of the children requiring a second attempt may have } \\
\text { differed in important ways between the two groups. }\end{array}$ \\
\hline
\end{tabular}




\begin{tabular}{|c|c|c|}
\hline $\begin{array}{l}\text { Ultimate fail- } \\
\text { ure }\end{array}$ & see Comments see Comments & $\begin{array}{l}\text { Although potentially influenced by the initial (allocated) } \\
\text { method of manipulation, this outcome reflected vari- } \\
\text { ous manipulation protocols that stipulated the choice of } \\
\text { method used for subsequent attempts. Overall failure at } \\
\text { the end of the protocol ranged from } 0 \text { to } 6 \text { ( } 4.1 \% \text { of } 148 \\
\text { episodes). }\end{array}$ \\
\hline
\end{tabular}

Recurrence see Comments see Comments

None of the trials reported this outcome.

within one

month)

${ }^{\star}$ The basis for the assumed risk (e.g. the median control group risk across studies) is provided in footnotes. The corresponding risk (and its $95 \%$ confidence interval) is

based on the assumed risk in the comparison group and the relative effect of the intervention (and its $95 \% \mathrm{Cl}$ ).

Cl: Confidence interval; RR: Risk Ratio

GRADE Working Group grades of evidence

High quality: Further research is very unlikely to change our confidence in the estimate of effect.

Moderate quality: Further research is likely to have an important impact on our confidence in the estimate of effect and may change the estimate.

Low quality: Further research is very likely to have an important impact on our confidence in the estimate of effect and is likely to change the estimate.

Very low quality: We are very uncertain about the estimate.

1. Young children: typically aged under 7 years; mean age around 2 years.

2. Median control group (supination-flexion) risk across studies

3. Evidence downgraded two levels for very serious risk of bias (selection and detection biases).

4. Evidence downgraded two levels for very serious risk of bias (selection, detection and incomplete outcome biases) and one level for inconsistency (two of the studies reported

in favour of pronation, whereas two studies reported no difference between the procedures)

5. Evidence downgraded two levels for very serious risk of bias (and one level for imprecision (there were just 9 events in the hyperpronation group) 


\section{B A C K G R O U N D}

\section{Description of the condition}

Pulled elbow (see Table 1 for synonyms) is a painful condition of acute onset, resulting in sudden loss of function in the affected limb of a child (Hagroo 1995). It is often caused when an adult (or taller person) holds the child by the hand while walking and suddenly pulls the child away from, for example, a dangerous situation, or merely drags the child up a curb or a step (Salter 1971); or when a child pulls away from an adult impulsively. This sudden pull on the arm in young children pulls the head of the radius (one of the two forearm bones) through the ring-shaped ligament at the elbow which may partially tear and become entrapped between the radial head (top part of the radius) and the capitellum (bottom end of the upper arm bone) (Matles 1967; Stone 1916). This results in subluxation (partial dislocation) of the radial head. Pulled elbow can also be caused by a fall or twist (Irie 2014).

This injury is easily diagnosed on the basis of history and physical examination. The typical presentation is a child who has suddenly cried out with pain and refused to use their arm after a pulling incident, when a snap or click might have been heard (Magill 1954). The arm is held slightly flexed and twisted inward (Asher 1976), with no swelling or bruising (Hardy 1978). Pain is usually felt at the elbow but pain may only be felt at the wrist or shoulder or both (Asher 1976; Griffin 1955). The elbow can usually be flexed and extended, but twisting of the forearm meets resistance and causes pain in the elbow (Hardy 1978).

Pulled elbow is a common injury in young children (Illingworth 1975 ; Teach 1996). Population-based incidence rates are scarce but an incidence of $1.2 \%$ per year in children aged 0 to 5 years in the Aberdeen city area of Scotland has been described and extrapolated to an annual incidence of 50,000 cases per year in England, Wales and Scotland (Jongschaap 1990). In Dutch general practice, an incidence was reported of 2.4 per 1000 person-years in children aged 0 to 5 years (Krul 2011). In the United States, the incidence of emergency care visits for pulled elbow was estimated at 2.7 per 1000 children aged 0 to 18 years (Brown 2009). The injury is most common in the left arm, and a median age at presentation between 2 and 2.5 years has been reported in several case series (Hagroo 1995; Illingworth 1975; Irie 2014; Rudloe 2012; Vitello 2014). Salter 1971 reported that the injury is most common in boys but a recent Japanese report of over 1300 cases found no sex difference (Irie 2014), and a review of over 1200 charts from the United States found $60 \%$ of cases were girls (Vitello 2014).

\section{Description of the intervention}

Pulled elbow is usually treated by manual intervention of the subluxed radial head. Various manoeuvres can be applied. Sometimes, these may be in conjunction with application of manual pressure over the radial head. Two manoeuvres are often recommended. One manoeuvre is supination (Nocton 2004; Thompson 2004), where the forearm is twisted or rotated outwards (palm of child's hand facing upwards), sometimes followed by flexion of the elbow (Sponseller 2006). While this has become standard practice, it is not always successful. Another manoeuvre is pronation, where the forearm is twisted or rotated inwards (palm of child's hand facing downwards). Both methods are generally safe, although bruising can occur and they can be painful. We found the terms 'pronation', 'forced pronation' and 'hyperpronation' are often not defined precisely; we have assumed that they are synonyms.

\section{How the intervention might work}

The purpose of all manipulative interventions is to reposition both the radial head and the annular ligament, thereby restoring the function of the arm and relieving the pain. In relation to the supination-flexion manoeuvre, Salter 1971 suggested that "the dramatic relief of pain and restoration of function after reduction of a pulled elbow (...) is explained by the release of the annular ligament from its pinched position and its return to a completely normal position".

As discussed in Bek 2009, the supination-flexion manoeuvre can be viewed as a reversal of the main mechanism of the injury. However, rotation of the radial head can be done either with supination or pronation and either may be sufficient to reposition the annular ligament to the radial head. Bek 2009 also considered that the supination manoeuvre acts against a greater mechanical block, thus putting the child at greater risk of pain during the procedure.

\section{Why it is important to do this review}

Pulled elbow is a common and very painful condition in young children. Although most textbooks recommend supination and flexion of the forearm (as opposed to pronation and other approaches), evidence for this advice is usually not presented. It is therefore important to identify and summarise the evidence in order to find the most effective and painless intervention. This is an update of a Cochrane review first published in 2009 (Krul 2009).

\section{O B JECTIVES}

To compare the effects (benefits and harms) of the different methods used to manipulate pulled elbow in young children. The primary comparison, as stated a priori, is the pronation method versus the supination method.

\section{METHODS}

\section{Criteria for considering studies for this review}

\section{Types of studies}

We included randomised controlled clinical trials or quasirandomised (method of allocating participants to a treatment which is not strictly random: e.g. by date of birth, hospital record number, alternation) trials evaluating manipulative interventions for pulled elbow in young children.

\section{Types of participants}

We included trials involving young children aged from birth up to adolescence, of either sex, diagnosed with an acute pulled elbow, either primary or recurrent. We excluded trials specifically focusing on older children or adults with this condition, as well as trials of children undergoing interventions for complete dislocation of the proximal radial head.

\section{Types of interventions}

We included trials focusing on various manoeuvres, such as pronation or supination of the forearm, used for the manual reduction of subluxation of the proximal radial head in the pulled 
elbow. We included interventions that took place in any setting (e.g. hospital, general practice, etc).

\section{Types of outcome measures}

\section{Primary outcomes}

The primary outcome was failure at the first attempt, where success was defined as immediate restoration of a pain-free, fully functioning arm. Failure was defined by the need for subsequent treatment, usually another attempt at reduction, and lack of spontaneous use of the arm by the child.

\section{Secondary outcomes}

When available, we also included results on the following outcomes:

- pain and distress during the intervention;

- bruising and other adverse effects;

- continued failure after second attempt using the same manoeuvre (added as an outcome during 2017 update);

- ultimate failure (e.g. in terms of the need for more intensive intervention);

- recurrence (within one month).

\section{Search methods for identification of studies}

\section{Electronic searches}

We searched the Cochrane Bone, Joint and Muscle Trauma Group Specialised Register (6 September 2016), the Cochrane Central Register of Controlled Trials (CENTRAL) (2016, Issue 8), MEDLINE (including Epub Ahead of Print, In-Process \& Other NonIndexed Citations and Ovid MEDLINE Daily) (1946 to 6 September 2016), Embase (1980 to 2016 Week 36), CINAHL (1937 to 6 September 2016), LILACS (Latin American and Caribbean Literature on the Health Sciences) (1982 to 6 September 2016), and PEDro (Physiotherapy Evidence Database) (1929 to 8 September 2016). For this update, the searches were limited to 2011 onwards. Details of the search strategies used for previous versions of the review are given in Krul 2012 and Krul 2009. We did not place any restrictions on language or publication status.

In MEDLINE, the subject-specific search was combined with the sensitivity-maximizing version of the Cochrane Highly Sensitive Search Strategy for identifying randomised trials (Lefebvre 2011) (see Appendix 1). Search strategies are also shown for the Cochrane Central Register of Controlled Trials, Embase, CINAHL, LILACS and PEDro (see Appendix 1). Search strategies included all synonyms for pulled elbow.

We searched the ISRCTN registry, World Health Organisation International Clinical Trials Registry platform (WHO ICTRP) and ClinicalTrials.gov for ongoing trials (8 September 2016) (see Appendix 1). We additionally ran a search of the Internet using Google Search (October 2016).

\section{Searching other resources}

We screened reference lists of relevant articles. We also contacted all authors who had published a trial on the treatment of the pulled elbow in the last 10 years, asking for additional studies.

\section{Data collection and analysis}

\section{Selection of studies}

Two review authors (MK and JCW) independently screened the results of the searches to identify studies that appeared to meet the inclusion criteria of the review, based on title and abstract. These studies were obtained in full text and the above two authors independently applied the review inclusion criteria. We resolved disagreements by discussion.

\section{Data extraction and management}

Using a data extraction form, two review authors (MK and JCW) independently extracted data from the included trials. MK and JCW entered data into RevMan. We resolved disagreements by discussion. We extracted results from graphs in trial reports when data were not provided in the text or tables. We attempted to contact authors of trials not reported in full journal publications for additional information or data or both.

\section{Assessment of risk of bias in included studies}

Two review authors (MK and JCW) independently assessed the included trials using Cochrane's tool for assessing risk of bias (Higgins 2008). Disagreements were resolved by discussion. Titles of journals, names of authors, or supporting institutions were not masked at any stage. The 'Risk of bias' tool incorporates assessment of randomisation (sequence generation and allocation concealment), blinding (of participants, treatment providers and outcome assessors), completeness of outcome data, selection of outcomes reported, and other sources of bias. We considered parent-rated and clinician-rated outcomes separately in our assessment of blinding and completeness of outcome data. Our other sources of bias were selection bias, where we assessed the risk of bias from imbalances in key baseline characteristics (age, time from injury, primary, or recurrent injury); and performance bias, where we checked for comparability in the experience of care providers and subsequent provision of treatment interventions, such as slings and advice.

\section{Measures of treatment effect}

Quantitative data reported in individual trial reports for the outcomes listed in the inclusion criteria are presented in the text and in the analyses, using risk ratios (RR) with 95\% confidence intervals $(\mathrm{Cl})$ for dichotomous outcomes. We planned to calculate mean differences (MD) for outcomes, such as pain, that were measured with a visual analogue scale. Where different instruments or measures were used, we planned to use the standardised mean difference (SMD).

\section{Unit of analysis issues}

Rarely, children may present with two pulled elbows, which are randomised to one procedure (e.g. Schunk 1990: out of 83 children, one child presented with two pulled elbows). There is no easy way to include this cluster effect in our analysis. When reported data allowed, we planned to perform sensitivity analyses, with and without these children. Children with recurrent pulled elbows within the same study population were treated the same way as children who presented with a pulled elbow for the first time. 


\section{Dealing with missing data}

Where appropriate, we planned to perform intention-to-treat analyses to include all children randomised to the intervention groups. We planned to investigate the effects of dropouts and exclusions by conducting worst and best case scenario analyses. We were alert to the potential mislabelling or non-identification of standard errors and standard deviations. Unless missing standard deviations could be derived from confidence interval data, we did not assume values in order to present these in the analyses.

\section{Assessment of heterogeneity}

We considered whether participant characteristics and the setting of the studies (e.g. emergency departments, general practice) were homogeneous enough from a clinical point of view to allow statistical pooling of the study results. Statistical heterogeneity was assessed by visual inspection of forest plots and calculation of the $\mathrm{I}^{2}$ statistic and $\mathrm{Chi}^{2}$ test for heterogeneity.

\section{Assessment of reporting biases}

If more than 10 studies become available in future, we plan to construct a funnel plot.

\section{Data synthesis}

We statistically pooled the results using a fixed-effect model to estimate summary effect measures and $95 \%$ confidence intervals when studies were clinically (e.g. regarding the setting, or age of the children) homogeneous. Where there was significant heterogeneity, we planned to see the effect of using a randomeffects model.

\section{Subgroup analysis and investigation of heterogeneity}

We planned subgroup analyses by age ( 0 to two years; two to five years; six years and above), clinical setting, and whether it was a primary or recurrent subluxation. Should subgroup analysis be done in a future update, we will investigate whether the results of subgroups were significantly different by inspecting the overlap of confidence intervals, and performing the test for subgroup differences available in RevMan.

\section{Sensitivity analysis}

Where possible, we performed sensitivity analyses examining various aspects of trial and review methodology, including the inclusion of trials at high risk of bias (specifically, from lack of allocation concealment).

\section{'Summary of findings' tables}

We prepared a 'Summary of findings' table for the main comparison (pronation versus supination). We used the GRADE approach to assess the quality of evidence for each of the listed outcomes as high, moderate, low or very low (see section 12.2 of the Cochrane Handbook for Systematic Reviews of Interventions, Schunemann 2011). We presented the following outcomes: failure (second attempt required), pain (preferably during the procedure), adverse effects (e.g. bruising), failure (continued failure after second attempt using same procedure as before), ultimate failure, and recurrence (within one month).

\section{RESULTS}

\section{Description of studies}

\section{Results of the search}

For this update (2011 to September 2016), we screened a total of 239 records from the following databases: Cochrane Bone, Joint and Muscle Trauma Group Specialised Register (5 records); CENTRAL (29), MEDLINE (24), Embase (30), CINAHL (91), PEDro (14), LILACS (0) the WHO ICTRP (9), ISRCTN registry (4) and ClinicalTrials.gov (33). We identified three additional records by checking references of included studies (Quan 1985; Schunk 1990) and a Google search (Asadi 2011).

The results from the previous searches (up to July 2011) are reported in Appendix 2.

The search update resulted in the identification of 11 potentially eligible studies, for which full reports were obtained. Upon study selection, we included five new trials (Asadi 2011 ; Garcia-Mata 2014; Gunaydin 2013; Guzel 2014; Schunk 1990) and excluded three studies (Dixon 2014; Quan 1985; Ruffing 2014). Dixon 2014 was previously identified as ongoing but after publication in 2014 it has now been excluded. We found one ongoing study (NCT01562535).

Overall, there are now nine included trials (Asadi 2011; Bek 2009; Garcia-Mata 2014; Green 2006; Gunaydin 2013; Guzel 2014; Macias 1998; McDonald 1999; Schunk 1990), four excluded studies (Dixon 2014; Quan 1985; Ruffing 2014; Taha 2000) and one ongoing trial (NCT01562535). One study, which was only reported as a conference abstract (Vidosavljevic 2006), awaits classification.

A flow diagram summarising the study selection process for this update is shown in Figure 1. 


\section{Figure 1. Study flow diagram}

4 studies included in previous
version of review (Krul 2012)

$$
\begin{aligned}
& 1 \text { study previously awaiting } \\
& \text { classification and } 1 \text { study } \\
& \text { previously ongoing (Krul 2012) }
\end{aligned}
$$

239 records identified through database searching (2011-2016)

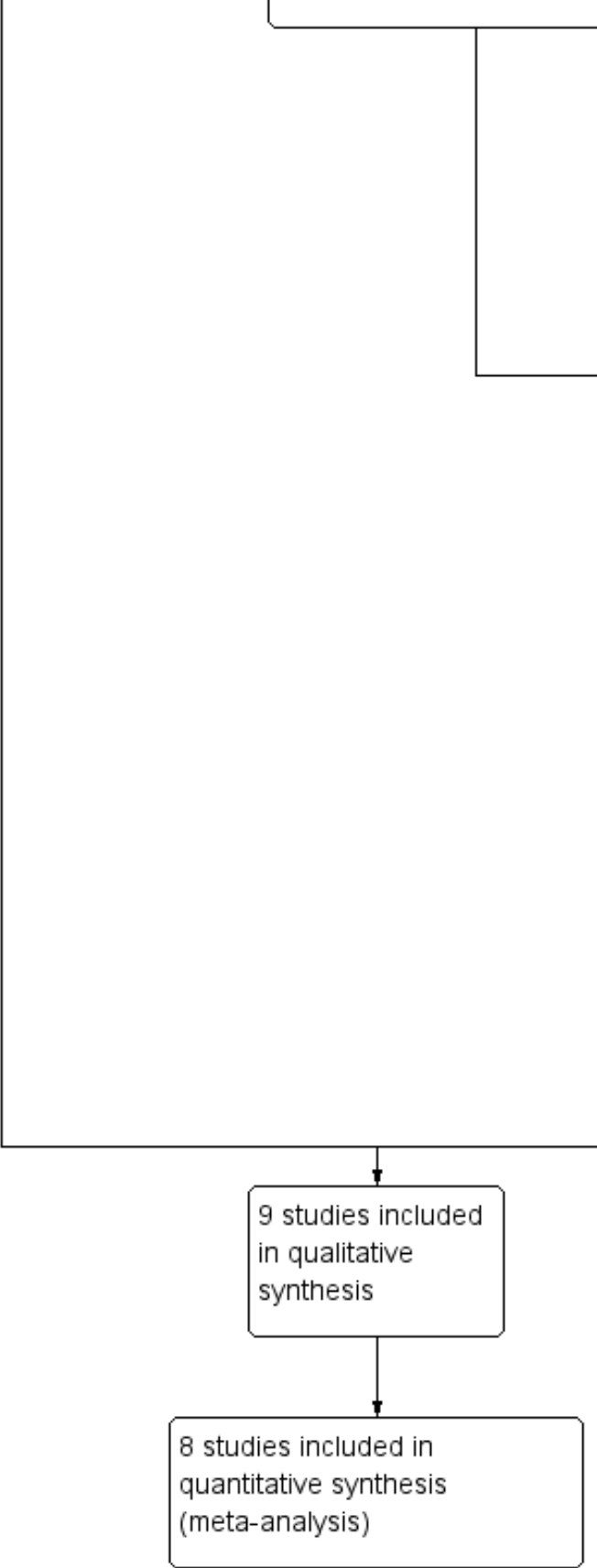

\section{Included studies}

Details of the individual trials are given in the Characteristics of included studies.

\section{Design}

Of the nine included trials, five were described as randomised trials (Garcia-Mata 2014; Green 2006; Guzel 2014; Macias 1998; McDonald 1999) but Garcia-Mata 2014 turned out to a quasi-randomised trial, based on day of admission (Garcia-Mata 2017). Four other studies were also quasi-randomised, by either day of month at admission (Gunaydin 2013; Schunk 1990) or date of birth of the child (Asadi 2011; Bek 2009).

\section{Setting}

Eight trials were performed in emergency departments or ambulatory care centres. Garcia-Mata 2014 was performed in a tertiary paediatric orthopaedic unit. One trial was conducted in Spain (Garcia-Mata 2014), one in Iran (Asadi 2011); three in Turkey 
(Bek 2009; Gunaydin 2013; Guzel 2014) and four in the USA (Green 2006; Macias 1998; McDonald 1999; Schunk 1990). All were singlecentre trials except for Macias 1998, which was conducted in four centres.

\section{Participants}

In total, 906 participants were recruited into the nine trials. The number of children in individual trials ranged from 75 (Guzel 2014) to 150 (Gunaydin 2013). The age range of the participants was 4.5 months to 7 years. The mean age was around 2 years, and, of the 896 children for whom baseline data were available, $58 \%$ were girls.

Schunk 1990 recruited three children with two episodes during the study; the duration of the intervals between the episodes was unknown.

\section{Interventions}

Eight included trials assigned children to either pronation (all involved hyperpronation) or supination (all were followed by flexion), with the exact methods described in varying and sometimes incomplete detail. Where described or illustrated, the child's elbow was often held at 90 degrees while the manoeuvre was performed; however, the elbow was held in (flexo)extension in Guzel 2014. McDonald 1999 followed pronation with active flexion at the elbow. One study compared two supination methods (Schunk 1990).

Where reported, interventions were carried out by physicians, residents (trainees) or medical students. All trials had a prespecified protocol detailing what were the actions to be taken in the case of initial failure. Six studies (Asadi 2011; Bek 2009; Gunaydin 2013; Guzel 2014; Macias 1998; McDonald 1999) stipulated that the same procedure should be used for the second attempt and the other three studies (Garcia-Mata 2014; Green 2006; Schunk 1990) stipulated that the alternate procedure should be used.

Studies differed in the waiting time to assess failure and make a second attempt: this was 10 minutes in Green 2006 and Guzel 2014, 15 minutes in Asadi 2011, Bek 2009, Macias 1998 and Schunk 1990, 20 minutes in Gunaydin 2013 and 30 minutes in McDonald 1999. Garcia-Mata 2014 did not report on this aspect.

\section{Outcomes}

All trials reported on success of the procedure, and also of subsequent attempts if the first attempt failed. Five studies defined what success comprised: Asadi 2011 and Bek 2009: "child started to use injured arm" (translation for Asadi 2011); Gunaydin 2013: "technique was deemed successful if the child reached for a toy or candy using the injured arm"; Macias 1998: "return of baseline function"; McDonald 1999: "the subject used the injured arm to reach for a piece of candy or a favorite toy"; and Schunk 1990: "child regained use of the arm".

Five studies also measured pain (Bek 2009; Green 2006; Gunaydin 2013; Guzel 2014; McDonald 1999). However, no outcome data on pain were presented by Bek 2009. Different instruments were used in the other four trials. In Guzel 2014, children who were old enough to communicate rated their pain with a faces pain rating scale. However, pain was not assessed during the procedure. Green 2006 and Gunaydin 2013 only reported on pain when treatment was successful. McDonald 1999 used a four-point ordinal scale.

No studies reported on adverse effects or recurrence.

\section{Excluded studies}

Three trials were excluded because they did not compare different methods of reducing pulled elbow (Dixon 2014; Ruffing 2014; Taha 2000). While the study design in Quan 1985 was unclear, we considered that it was not a randomised or quasi-randomised trial. Further details are provided in Characteristics of excluded studies.

\section{Ongoing studies}

There is one ongoing trial (NCT01562535); see Characteristics of ongoing studies. NCT01562535 compared pronation versus supination, with a planned sample size of 90 participants. Contact with one of the authors (September 2014) revealed that recruitment had not yet started.

\section{Risk of bias in included studies}

Figure 2 and Figure 3 summarise our assessment of the risk of bias for the included trials. Comments on the specific items we assessed are given below. 
Figure 2. Methodological quality summary: review authors' judgements about each methodological quality item for each included study.

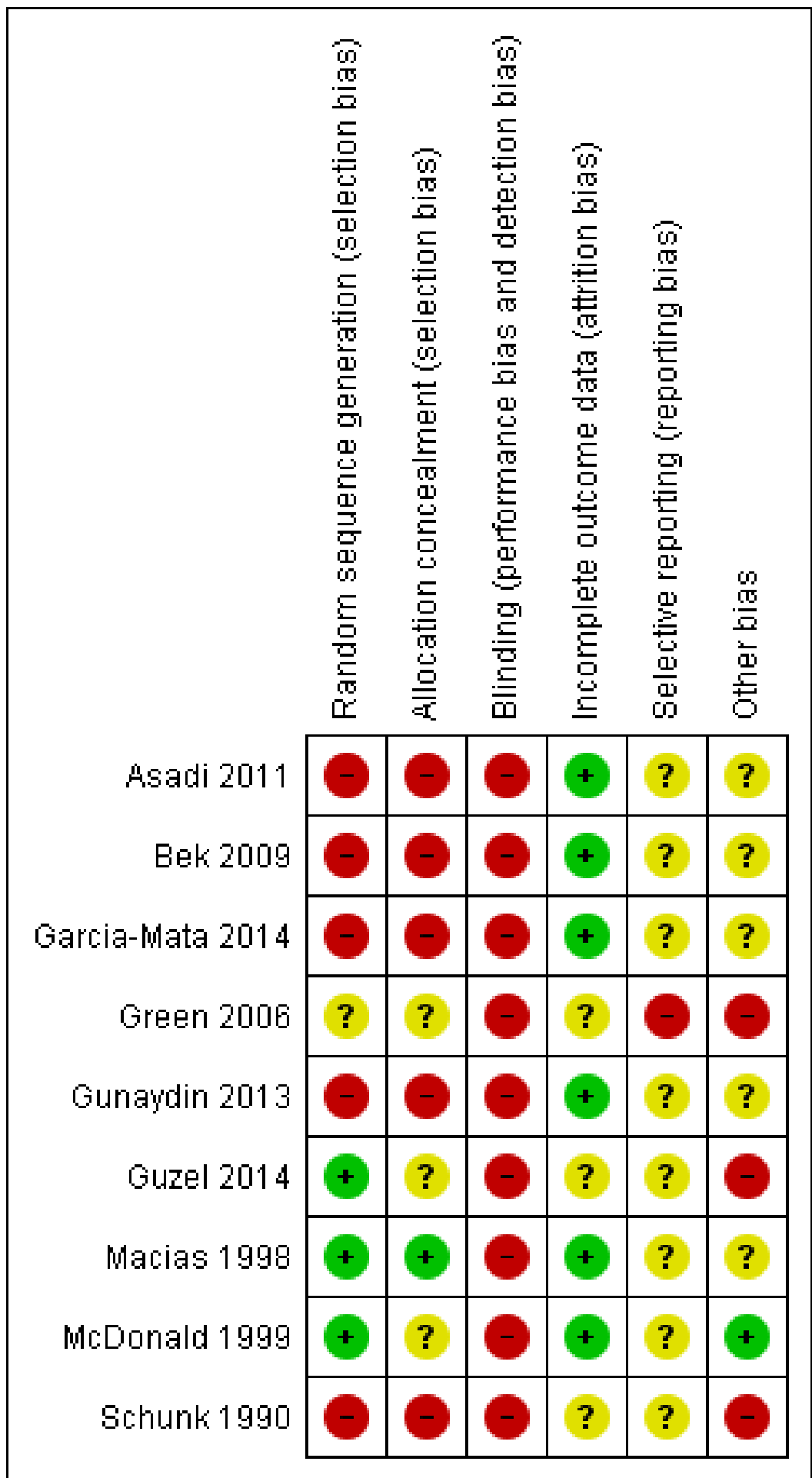


Figure 3. Methodological quality graph: review authors' judgements about each methodological quality item presented as percentages across all included studies.

\section{Random sequence generation (selection bias) \\ Allocation concealment (selection bias) \\ Blinding (performance bias and detection bias)}

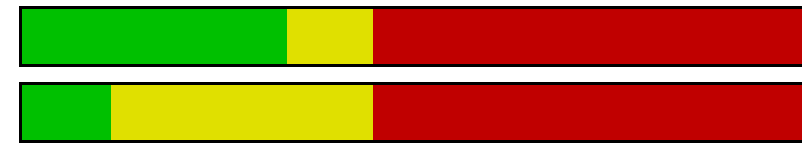

Incomplete outcome data (attrition bias)

Selective reporting (reporting bias)

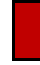

Other bias

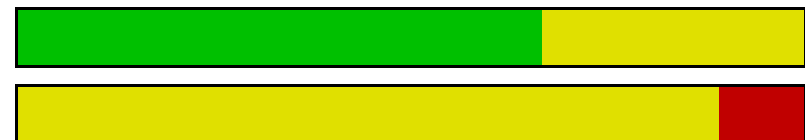

Selective reporting (reporting bias)
Other bias

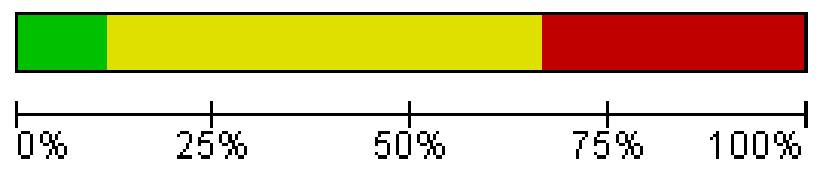

\section{Allocation}

Three studies describing suitable methods of random sequence generation (use of a "randomizations table" or computer generated) were judged at 'low' risk for this item (Guzel 2014; Macias 1998; McDonald 1999). One study did not describe this and was judged to be at 'unclear' risk (Green 2006). Five studies were quasi-randomised (Asadi 2011; Bek 2009; Garcia-Mata 2014; Gunaydin 2013; Schunk 1990): treatment being assigned either according to the child's birthday (odd or even) or according to the day of admission. These studies were judged at 'high' risk of selection bias since no random sequence was generated and allocation was not concealed. Macias 1998 reported that allocation was concealed to the attending physician, and so risk of bias was considered low on this item. Allocation concealment was not mentioned in three studies (Green 2006; Guzel 2014; McDonald 1999). The associated risk of selection bias in these trials was judged as 'unclear'.

\section{Blinding}

Blinding of either the participants (hardly possible), the treatment providers (not possible) or the outcome assessors (which may be possible) was not done in any of the studies. However, the blinding of child and parents for the manipulation technique was probably not relevant, as they might not be aware of the different techniques nor have any preference. The lack of blinding, especially of treatment providers, was an important source of potential bias in all nine trials.

\section{Incomplete outcome data}

The six studies that analysed and reported on all randomised participants were judged at 'low' risk of attrition bias. The other three studies were judged at 'unclear' risk, reflecting concerns over missing data, data discrepancies or both (Green 2006; Guzel 2014; Schunk 1990).

\section{Selective reporting}

Trial registration and protocols were not available for any of the included studies. In Green 2006, pain was only recorded for successful attempts and not for the 9 (out of 72) participants with unsuccessful attempts. We considered this trial as having a 'high' risk of selective reporting bias.

\section{Other potential sources of bias}

Three trials were considered at 'high' risk of other bias. There was a considerable difference between the study groups in the time elapsed since the injury in Green 2006. Faults in the reporting of Guzel 2014 were of major concern. In Schunk 1990, treatment allocation was not according to protocol in an unknown number of participants, resulting in a considerable baseline imbalance between treatment arms (51:25). Additionally, 11 participants were not treated according to one of the treatment methods.

Lack of information to determine whether there was baseline comparability, discrepancies or small differences between key baseline characteristics were reasons for 'unclear' risk judgements in four trials (Asadi 2011; Bek 2009; Garcia-Mata 2014; Macias 1998). There was no important imbalance in McDonald 1999.

Care providers and provision of care seemed comparable in the two groups in all trials and we found no differences between groups with respect to additional treatment they received. There was, however, no information on the experience of the attending physicians in reducing a pulled elbow. In some of the studies, at least a part of the interventions were performed by trainees (Bek 2009, Gunaydin 2013; McDonald 1999); training was specifically provided in two of these (Bek 2009; McDonald 1999). We found no differences between groups with respect to additional treatment they received.

\section{Effects of interventions}

See: Summary of findings for the main comparison 


\section{Comparison 1: Pronation versus supination}

Eight studies compared hyperpronation (or forced pronation) with supination-flexion.

\section{Primary outcome: failure after first attempt}

We considered the eight studies were sufficiently similar in terms of study populations and settings to warrant pooling data on failure rates. All eight trials reported fewer failures after hyperpronation (RR 0.35 favouring hyperpronation, $95 \% \mathrm{Cl} 0.25$ to $0.50 ; 811$ participants, 8 studies; $I^{2}=25 \%$; low-quality evidence downgraded two levels for very serious risk of bias; Figure 4, Analysis 1.1).

Figure 4. Forest plot of comparison: 1 Pronation versus supination, outcome: 1.1 Failure: second attempt required.

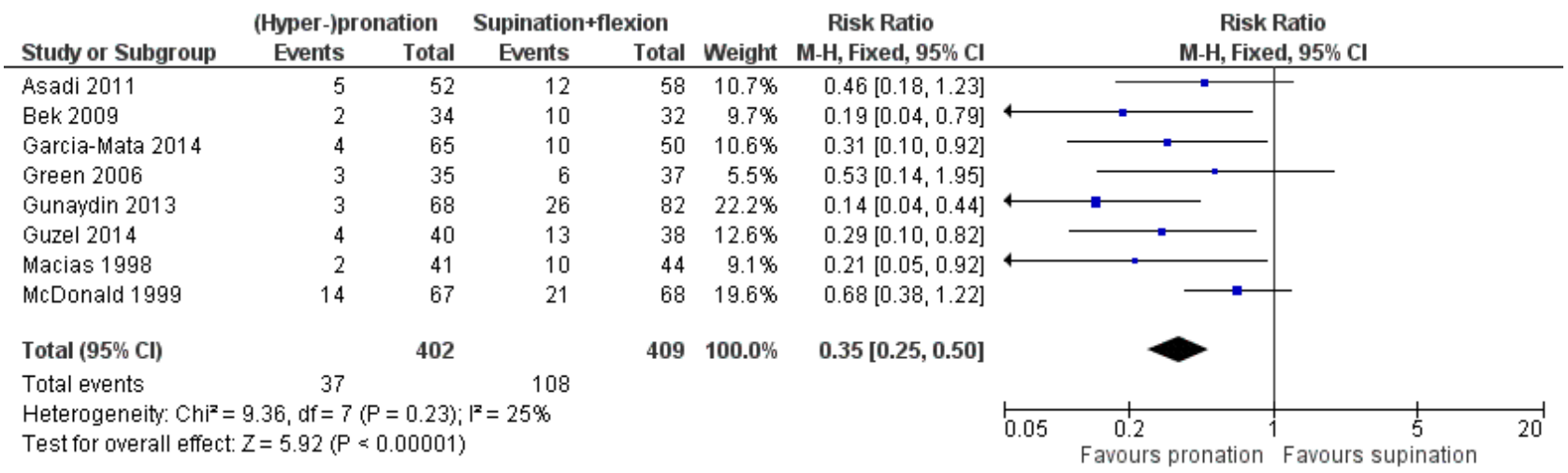

The failure rates of both methods varied between studies: for hyperpronation these ranged from 4.4\% in Gunaydin 2013 to $20.9 \%$ in McDonald 1999; and for supination and flexion these ranged from $16.2 \%$ in Green 2006 to 34.2\% in Guzel 2014. Based on the pooled data, with a mean failure rate of $26.4 \%$ when using the supination method (thus around one in four first attempts fail) and $9.2 \%$ when using the hyperpronation method, the number needed to treat (NNT) for the hyperpronation method was $6(95 \% \mathrm{Cl} 5$ to 9). This means that six children would need to be treated with the hyperpronation method rather than the supination-flexion method to avoid one additional failure at the first attempt.

\section{Subgroup and sensitivity analyses}

Our planned subgroup analyses by age ( 0 to two years; two to five years; six years and above), clinical setting, and whether the subluxation was primary or recurrent were not possible due to lack of data.

For our primary outcome, we performed several sensitivity analyses, which tested the effects of excluding data from the four quasi-randomised studies (Asadi 2011; Bek 2009; Garcia-Mata 2014; Gunaydin 2013); excluding Green 2006, which was potentially confounded by the difference in mean time from injury between the two groups; and excluding data from the 17 children in GarciaMata 2014 who had already undergone one or more manipulations, all using the supination-flexion method before entering the main study. None of these analyses materially changed the findings, which continued to favour hyperpronation (Table 2).

\section{Secondary outcomes}

\section{Pain and distress}

Pain was measured in five of the trials addressing this comparison (Bek 2009; Green 2006; Gunaydin 2013; Guzel 2014; McDonald 1999). However, they all used very different measures and Bek 2009, which did not state how pain had been measured, did not present separate pain data, instead combining it with clinician's perceived ease of the manoeuvre. Data for pain were not available for pooling. The pain results in the individual trials are summarised below.

In Green 2006, pain was only assessed for successful attempts. Green 2006 found that the difference in the visual analogue scores (10 cm scale) favoured pronation. The difference was $0.7 \mathrm{~cm}$ as perceived by physicians (reported $\mathrm{P}=0.11$ ); $1.0 \mathrm{~cm}$ by nurses (reported $P=0.03$ ) and $1.7 \mathrm{~cm}$ by parents (reported $P=0.04$ ). This last finding exceeded the minimal clinically significant difference of $1.3 \mathrm{~cm}$ stipulated by the trialists.

McDonald 1999 reported, using a four-point ordinal score, that the treating physicians perceived the pronation method to be significantly less painful than supination (reported $P=0.013$, with an estimated 1-point difference), but that parental pain scores during reduction were similar for both procedures (reported $\mathrm{P}=$ $0.169)$.

Gunaydin 2013 used the Modified Children's Hospital of Eastern Ontario Pain Scale before, during, and after the procedure. Pain scale values during and after the procedure were not different between the two groups; reported $\mathrm{P}$ values were 0.801 (during) and 0.914 (after the procedure).

Guzel 2014 used the Wong-Baker Faces Pain Rating Scale in children who were able to communicate, and the Face, Legs, Cry, Consolability Scale to be scored by research assistants if children were not able to communicate. Pain was assessed before and after the procedure, but not during the procedure. No differences were found after the procedure (reported $\mathrm{P}=0.462$ ).

Overall, two out of four studies found that pronation may be less painful, whereas two found no difference between the two procedures. The quality of the evidence for this outcome was judged to be very low due to very serious risk of bias (notably, selection bias, lack of assessor blinding and incomplete data) and serious inconsistency. 


\section{Bruising and other adverse effects}

Bruising and other adverse effects were not reported in any of the studies.

\section{Failure after second attempt using the same procedure}

All studies reported failure after the second attempt, but the same procedure as in the first attempt was used only in six trials. The cumulative effect of two manipulations using hyperpronation again resulted in fewer reduction failures than two manipulations using supination-flexion (RR $0.16,95 \% \mathrm{Cl} 0.09$ to $0.32 ; 624$ participants; 6 studies; $12=0 \%$; very low-quality evidence downgraded two levels for very serious risk of bias and one level for serious imprecision; Analysis 1.2). Hyperpronation, when used for a second time, resulted in a greater percentage of successful reductions (70\%: 21/30 primary failures) than did supinationflexion (30\%; $28 / 92$ primary failures) in these six studies. Thus, while both procedures were successful on the second attempt, a second attempt using hyperpronation again appeared more effective than one using supination-flexion.

\section{Ultimate failure}

Ultimate failure was reported in most studies. However, since the study protocols differed with respect to what to do after the first attempt failed and after any subsequent failure, it is inappropriate to attribute this outcome to the first-used allocated manipulation method. This varied from no ultimate failures after the end of the manipulation protocol (Bek 2009; Gunaydin 2013) to six ultimate failures (4.1\% of 148 participants) in McDonald 1999; we could not determine this outcome from Asadi 2011 and Guzel 2014. These data are summarised in Table 3.

\section{Recurrence (within one month)}

Recurrence was not reported as an outcome in all eight studies. Of note, however, is that five of the 85 children included by Macias 1998 were included twice, due to a recurrence. Only one of these recurred within one month (a few days).

\section{Comparison 2: Supination-extension versus supination-flexion}

This comparison was made only in Schunk 1990, a seriously flawed and inadequately-reported quasi-randomised trial reporting outcome data for 76 episodes ( 72 to 76 children). The manipulation protocol for Schunk 1990 involved cross-over if the first attempt failed after 15 minutes.

\section{Primary outcome: failure after first attempt}

In the group treated with supination and extension, eight of 25 repositions failed. In the group treated with supination and flexion, ten of 51 repositions failed. An exploratory analysis showed no clear difference between the two reduction methods: RR $1.63,95 \% \mathrm{Cl}$ 0.74 to 3.62; very low-quality evidence reflecting downgrading for very serious risk of bias and serious imprecision; see Analysis 2.1).

\section{Secondary outcomes}

Schunk 1990 did not report on pain and distress, adverse effects or recurrence within one month. The second attempt, using the opposite manoeuvre, failed in 10 children. Ultimate failure occurred in three children (3.9\% of 76 episodes); all three received a splint and left the emergency department without full use of their injured arm. All three children had normal use of their arm at subsequent orthopaedic follow-up. Notably, Schunk 1990 included three children with two episodes during the study; there was no information on timing.

\section{DISCUSSION}

\section{Summary of main results}

Eight of the nine trials included in this review compared hyperpronation with supination-flexion for the primary reduction method for treating pulled elbow (subluxation of the radial head) in young children, all of whom were younger than seven years old. All seven trials were at high risk of bias. The results for this comparison are summarised in Summary of findings for the main comparison. There was low-quality evidence (downgraded two levels for very serious risk of bias) of a significantly lower risk of failure at first attempt (our primary outcome) after manipulation with hyperpronation than with supination-flexion (RR 0.35; 95\% $\mathrm{Cl} 0.25$ to $0.50 ; 811$ participants, 8 trials). Based on an illustrative risk of 268 failures at first attempt per 1000 children treated using supination-flexion, this amounted to 174 fewer failures per 1000 children treated using hyperpronation ( $95 \% \mathrm{Cl} 134$ to 201 fewer). Based on risk difference data, we also estimated a number needed to treat of 6 ( $95 \% \mathrm{Cl} 5$ to 8$)$; this means that six children would need to be treated with the hyperpronation method rather than the supination-flexion method to avoid one additional failure at the first attempt.

The very low-quality evidence (from four studies; downgraded three levels for very serious risk of bias and serious inconsistency) for pain during or after manipulation means that it is uncertain whether there is or is not a difference between pronation and supination-flexion. There was very low-quality evidence from six studies that repeat pronation may be more effective than repeat supination-flexion for the second attempt. The remaining outcomes were either not reported (adverse effects, recurrence) or unsuitable for pooling (ultimate failure). Ultimate failure, reported for overall population only, because of the differences in the study protocols with respect to what to do after the first attempt failed, ranged from no ultimate failures in two studies to six failures $(4.1 \%$ of 148 episodes) in one study.

The single quasi-randomised trial (data for 76 episodes) comparing two methods of supination (supination followed by extension versus supination followed by flexion) was at very serious risk of bias. It provided very low-quality evidence (downgraded three levels for very serious risk of bias and serious imprecision) of no clear difference in failure at first attempt between the two methods.

\section{Overall completeness and applicability of evidence}

The objective of this review was to compare the effectiveness of, and pain associated with, different methods for manipulating the pulled elbow in young children. Eight of nine included studies addressed our stated primary comparison of pronation versus supination methods. We believe this review provided a relevant answer to the question of effectiveness of these basic procedures, but the evidence was still incomplete and susceptible to bias. In particular, there was insufficient or no evidence on pain, adverse effects or recurrence. Trial settings, care providers and the study populations were comparable in the seven trials. Also, the study protocols with respect to procedure and waiting times appeared to be realistic and applicable in clinical practice. Hence, the findings of these trials would apply more generally. However, our planned 
subgroup analyses by age ( 0 to two years; two to five years; six years and above) and by clinical setting were not possible.

The single trial comparing two methods of supination was of very low methodological quality.

\section{Quality of the evidence}

Overall, the quality of evidence for individual outcomes was either low ('further research is very likely to have an important impact on our confidence in the estimate of effect') or very low ('we are very uncertain about the estimate'). The main reason for downgrading the quality of the evidence by two levels for all outcomes was the very serious risk of bias due to selection bias (the majority of the trials were quasi-randomised) and performance and detection biases reflecting the lack of blinding. We did not downgrade for publication bias because the number of included studies was too small to assess this.

As noted in Summary of findings for the main comparison, we downgraded the evidence for pain one further level for serious inconsistency and the evidence for continued failure after second attempt using the same procedure as before by one further level for serious imprecision. For the study comparing two supination methods, we downgraded the evidence by one further level for serious imprecision.

\section{Potential biases in the review process}

Although our search was extensive, we cannot exclude the possibility that we have missed relevant evidence. We tried to contact the authors of the original studies but only two replied and in only one of these did it result in clarification of methods. Our search of grey literature, the pursuit of trials listed in clinical trial registers and the fact that we applied no restrictions based on language or publication status aimed to avoid publication bias, location bias, citation bias, language bias and outcome reporting bias. Given there were only eight studies available addressing the same comparison, we were unable to explore whether publication bias could have occurred by constructing a funnel plot.

\section{Agreements and disagreements with other studies or reviews}

We found four other reviews. Lewis 2003, which only included the studies by McDonald 1999 and Macias 1998, concluded that pronation with or without elbow flexion should be "the first line method of reduction for pulled elbows". Lewis 2003 pointed out that lack of blinding was a key weakness of these two trials. A later Dutch review (Knuistingh Neven 2008), which included the studies by Green 2006; Macias 1998; McDonald 1999 but also Taha 2000 (which we excluded), also concluded that the pronation method was more effective than the supination method. More recently, Curtis 2012 published a systematic review, discussing the limitations of the few randomised trials that have been performed. Bexkens 2017 included seven studies which were also included in this update but did not include Asadi 2011. The pooled results and conclusions of Bexkens 2017 are very much in line with those in our review update.

Several textbooks still suggest the supination method as the only or preferred method (e.g. Nocton 2004; Thompson 2004; Bachman 2010; Erickson 2016). This is not supported by the findings of this systematic review, which provided some evidence that pronation might be more effective and less painful than supination. Other textbooks also mentioned hyperpronation (Burg 2008; Joffe 2010). Lucas 2016 described hyperpronation (also labelled 'superpronation') as the preferred method. A recent instructional paper also mentioned both procedures (Aylor 2014). One excluded study (Dixon 2014) compared trained nurses (using hyperpronation at the first attempt) with physicians (who used either hyperpronation or supination-flexion). It is notable that hyperpronation was selected as the method for the nurses in this study, perhaps indicating some perception of it being an easier method.

\section{AUTHORS' CONCLUSIONS}

\section{Implications for practice}

Eight studies comparing the hyperpronation method with the supination-flexion method in young children provided low-quality evidence that, at first attempt, pronation may be more effective. There was very low-quality evidence that repeat pronation may be more effective than repeat supination-flexion for the second attempt. We are uncertain whether pain during or after pronation differs from that during or after supination-flexion as the quality of the evidence was very low and contradictory. None of the studies reported on bruising or other adverse effects, or recurrence.

Many textbooks continue to recommend supination as the preferred method; this notably is not supported by the findings of this systematic review.

\section{Implications for research}

It would be useful to replicate the head-to-head comparison of pronation versus supination in a larger randomised controlled trial that conforms to high methodological and reporting standards. It is important to also ensure comparability in competence of personnel in performing the reduction methods. As well as rigorous and blinded assessment of failure, recorded outcomes should include pain and distress during the intervention (both preferably blinded), adverse effects, ultimate failure, and recurrence. This further research would improve the evidence for the most effective method. However, given the fact that all eight trials comparing pronation versus supination favoured pronation, it is doubtful whether the question is still in equipoise. It may therefore be worthwhile to do a survey among physicians to assess barriers and facilitators of the two techniques before embarking on a new randomised trial.

\section{ACKNOWLEDGEMENTS}

We are grateful to Meisam Abdar for his translation of Asadi 2011 and to Serafín García-Mata for providing details of the design of their study (Garcia-Mata 2014).

The authors would like to acknowledge valuable comments at protocol and review stages from: Karen Black, Lesley Gillespie, Helen Handoll, Brian Rowe, Cathie Sherrington, Sue Stephen, Ben Vandemeer and Janet Wale. We particularly thank Joanne Elliott for her help with the search strategy and Lindsey Elstub for her help during editorial processing. We thank Ella Curtis for providing her paper.

This project was supported by the National Institute for Health Research via Cochrane Infrastructure funding to the Cochrane 
Bone, Joint and Muscle Trauma Group. The views and opinions expressed therein are those of the authors and do not necessarily reflect those of the Systematic Reviews Programme, NIHR, NHS or the Department of Health. 
R E F E R E N C E S

\section{References to studies included in this review}

Asadi 2011 \{published data only\}

Asadi K, Mardani M. Comparison of the method of wrist supination with elbow flexion as classical method with hyperpronation method in reduction of radial head subluxation

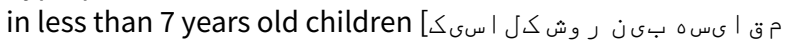

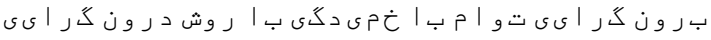

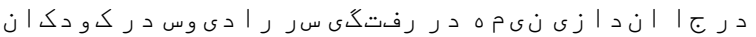

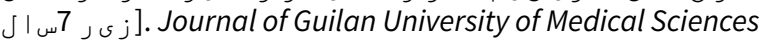
2011;20(77):55-60.

\section{Bek 2009 \{published data only\}}

Bek D, Yildiz C, Köse Ö, Şehirlioğlu A, Başbozkurt M. Pronation versus supination maneuvers for the reduction of 'pulled elbow': a randomized clinical trial. European Journal of Emergency Medicine 2009;16(3):135-8. [MEDLINE: 19262394]

\section{Garcia-Mata 2014 \{published and unpublished data\}}

Garcia-Mata S. Method of randomisation and confirmation of lack of separate group data on recurrence [personal communication]. Email to: $\mathrm{H}$ Handoll 6 April 2017.

* García-Mata S, Hidalgo-Ovejero A. Efficacy of reduction maneuvers for "pulled elbow" in children: a prospective study of 115 cases. Journal of Pediatric Orthopedics 2014;34(4):432-6. [MEDLINE: 24322628]

\section{Green 2006 \{published data only\}}

Green DA, Linares MY, Garcia Peña BM, Greenberg B, Baker RL. Randomized comparison of pain perception during radial head subluxation reduction using supination-flexion or forced pronation. Pediatric Emergency Care 2006;22(4):235-8. [MEDLINE: 16651912]

\section{Gunaydin 2013 \{published data only\}}

Gunaydin YK, Katirci Y, Duymaz H, Vural K, Halhalli HC, Akcil M, et al. Comparison of success and pain levels of supination-flexion and hyperpronation maneuvers in childhood nursemaid's elbow cases. American Journal of Emergency Medicine 2013;31(7):1078-81. [MEDLINE: 23702058]

\section{Guzel 2014 \{published data only\}}

Guzel M, Salt O, Demir MT, Akdemir HU, Durukan P, Yalcin A. Comparison of hyperpronation and supination-flexion techniques in children presented to emergency department with painful pronation. Nigerian Journal of Clinical Practice 2014;17(2):201-4. [MEDLINE: 24553032]

\section{Macias 1998 \{published data only\}}

* Macias CG, Bothner J, Wiebe R. A comparison of supination/ flexion to hyperpronation in the reduction of radial head subluxations. Pediatrics 1998;102(1):e10. [MEDLINE: 9651462]

Macias CG, Wiebe R, Bothner J. History and radiographic findings associated with clinically suspected radial head subluxations. Pediatric Emergency Care 2000;16(1):22-5. [MEDLINE: 10698138]
McDonald 1999 \{published data only\}

McDonald J, Whitelaw C, Goldsmith LJ. Radial head subluxation: comparing two methods of reduction. Academic Emergency Medicine 1998;6(7):715-8. [MEDLINE: 10433531]

\section{Schunk 1990 \{published data only\}}

Schunk JE. Radial head subluxation: epidemiology and treatment of 87 episodes. Annals of Emergency Medicine 1990;19(9):1019-23.

\section{References to studies excluded from this review}

Dixon 2014 \{published data only\}

* Dixon A, Clarkin C, Barrowman N, Correll R, Osmond MH, Plint AC. Reduction of radial-head subluxation in children by triage nurses in the emergency department: a clusterrandomized controlled trial. Canadian Medical Association Journal 2014;186(9):E317-23. [MEDLINE: 24664649]

Dixon AC. Reduction of radial head subluxation in children via a nurse initiated pathway: A randomized control trial. clinicaltrials.gov/show/NCT00993954 (accessed 22 July 2011).

Quan 1985 \{published data only\}

Quan L, Marcuse EK. The epidemiology and treatment of radial head subluxation. American Journal of Diseases in Childhood 1985;139:1194-7.

Ruffing 2014 \{published data only\} Ruffing T, Winkler $\mathrm{H}$, Muhm M. ProFI reduction of pediatric pulled elbow [Die ProFI-Reposition der Pronatio dolorosa infantum]. Der Unfallchirurg 2014;117:1105-11.

\section{Taha 2000 \{published data only\}}

Taha AM. The treatment of pulled elbow: a prospective randomized study. Archives of Orthopaedic and Trauma Surgery 2000;120(5-6):336-7. [MEDLINE: 10853908]

\section{References to studies awaiting assessment}

Vidosavljevic 2006 \{published data only (unpublished sought but not used)\}

Vidosavljevic M, Pejanovic J, Jovanovic B, Brdar R, Abramovic D, Ducic $S$, et al. Pronatio dolorosa - radial head subluxation a comparison of reduction techniques: supination/flexion versus hyperpronation - preliminary results [abstract]. Journal of Bone and Joint Surgery - British Volume 2006;88(Suppl 1):131-2.

\section{References to ongoing studies}

NCT01562535 \{published data only\}

NCT01562535. A clinical trial of pronation versus supination maneuvers for the reduction of the pulled elbow. apps.who.int/ trialsearch/Trial2.aspx?TrialID=NCT01562535 (accessed 16 December 2016). 


\section{Additional references}

\section{Asher 1976}

Asher MA. Dislocations of the upper extremity in children. Orthopedic Clinics of North America 1976;7(3):583-91.

\section{Aylor 2014}

Aylor M, Anderson JD, Vanderford P, Halsey M, Lai S, Braner D. Reduction of pulled elbow. New England Journal of Medicine 2014;371(21):e32.1-32.3.

\section{Bachman 2010}

Bachman D. Musculoskeletal trauma. In: Fleisher GR, Ludwig S editor(s). Textbook of Pediatric Emergency Medicine. 6th Edition. Philadelphia: Lippincott Williams \& WIlkins, 2010.

\section{Bexkens 2017}

Bexkens R, Washburn FJ, Eygendaal D, Van den Bekerom MP, Oh LS. Effectiveness of reduction maneuvers in the treatment of nursemaid's elbow: A systematic review and meta-analysis. American Journal of Emergency Medicine 2017;35(1):159-63.

\section{Brown 2009}

Brown D. Emergency department visits for nursemaid's elbow in the United States, 2005-2006. Orthopaedic Nursing 2009;28(4):161-2.

\section{Burg 2008}

Burg MD, Ten Napel SC. Upper extremity trauma. In: Baren JM, Rothrock SG, Brennan JA, Brown L editor(s). Pediatric Emergency Medicine. Philadelphia: Saunders Elsevier, 2008:175.

\section{Curtis 2012}

Curtis E. Managing 'pulled elbow' in the paediatric emergency department. Emergency Nurse 2012;19(9):24-7.

\section{Erickson 2016}

Erickson MA, Rhodes J, Niswander C. Orthopedics. In: Hay WW Jr, Levin MJ, Deterding RR, Abzug MJ editor(s). Current Diagnosis \& Treatment: Pediatrics. 23rd Edition. New York: McGraw-Hill, 2016.

\section{Garcia-Mata 2017}

Garcia-Mata S. Method of randomisation and confirmation of lack of separate group data on recurrence [personal communication]. Email to: $\mathrm{H}$ Handoll 6 April 2017.

\section{Griffin 1955}

Griffin ME. Subluxation of the head of the radius in young children. Pediatrics 1955;15(1):103-6.

\section{Hagroo 1995}

Hagroo GA, Zaki HM, Choudhary MT, Hussain A. A pulled elbow - not the effect of the hypermobility of joints. Injury 1995;26(10):687-90.

\section{Hardy 1978}

Hardy RH. Nursemaid's elbow. Journal of the Royal College of General Practitioners 1978;28(189):224-6.

\section{Higgins 2008}

Higgins JPT, Altman DG (editors). Chapter 8: Assessing risk of bias in included studies Table 8.5a. In: Higgins JPT, Green $\mathrm{S}$ (editors). Cochrane Handbook for Systematic Reviews of Interventions Version 5.0.1.(updated September 2008). The Cochrane Collaboration, 2008. Available from www. cochranehandbook.org.

\section{Illingworth 1975}

Illingworth CM. Pulled elbow: a study of 100 patients. British Medical Journal 1975;2(5972):672-4.

\section{Irie 2014}

Irie T, Sono T, Hayama Y, Matsumoto T, Matsushita M. Investigation on 2331 cases of pulled elbow over the last 10 years. Pediatric Reports 2014;6(2):26-8.

\section{Joffe 2010}

Joffe MD, Loiselle JM. Orthopedic emergencies. In: Fleisher GR, Ludwig S editor(s). Textbook of Pediatric Emergency Medicine. 6th Edition. Philadelphia: Lippincott Williams \& WIlkins, 2010.

\section{Jongschaap 1990}

Jongschaap HC, Youngson GG, Beattie TF. The epidemiology of radial head subluxation ('pulled elbow') in the Aberdeen city area. Health Bulletin 1990;48(2):58-61.

\section{Knuistingh Neven 2008}

Knuistingh Neven A, Eekhof J. Nursemaid's elbow [Zondagmiddagarmpje]. Huisarts en Wetenschap 2008;51(13):688-90.

\section{Krul 2011}

Krul M. Musculoskeletal problems in children in general practice [thesis] (repub.eur.nl/pub/26723). Rotterdam: Erasmus University, 2011.

\section{Lefebvre 2011}

Lefebvre C, Manheimer E, Glanville J. Search filters. In: Higgins JPT, Green S, editor(s). Cochrane Handbook for Systematic Reviews of Interventions Version 5.1.0 (updated March 2011). The Cochrane Collaboration, 2011. Available from handbook.cochrane.org.

\section{Lewis 2003}

Lewis D. Reduction of pulled elbows. Emergency Medicine Journal 2003;20(1):61-2.

\section{Lucas 2016}

Lucas JK. Nursemaid's elbow. In: Ganti L editor(s). Atlas of Emergency Medicine Procedures. New York: Springer, 2016:731-5.

\section{Magill 1954}

Magill HK, Aitken AP. Pulled elbow. Surgery, Gynecology \& Obstetrics 1954;98(6):753-6.

\section{Matles 1967}

Matles AL, Eliopoulos K. Internal derangement of the elbow in children. International Surgery 1967;48(3):259-63. 


\section{Nocton 2004}

Nocton JJ. Chapter 44 Arthritis. In: Kliegman RM, Greenbaum LA, Lye PS editor(s). Practical Strategies in Pediatric Diagnosis and Therapy. 2nd Edition. Philadelphia: Elsevier Saunders, 2004:820. [ISBN 0721691315]

\section{Rudloe 2012}

Rudloe TF, Schutzman S, Lee LK, Kimia AA. No longer a "nursemaid's" elbow: mechanisms, caregivers, and prevention. Pediatric Emergency Care 2012;28(8):771-4.

\section{Salter 1971}

Salter RB, Zaltz C. Anatomic investigations of the mechanism of injury and pathologic anatomy of "pulled elbow" in young children. Clinical Orthopaedics \& Related Research 1971;77:134-43.

\section{Schunemann 2011}

Schunemann HJ, Oxman AD, Vist GE, Higgins JPT, Deeks JJ, Glaziou P, et al. Chapter 12: Interpreting results and drawing conclusions. In: Higgins JPT, Green S, editor(s), Cochrane Handbook for Systematic Reviews of Interventions Version 5.1.0 (updated March 2011). The Cochrane Collaboration, 2011. Available from handbook.cochrane.org.

\section{Sponseller 2006}

Sponseller PD. Bone and joint diseases. In: McMillan JA editor(s). Oski's Pediatrics, Principles and Practice. 4th Edition. Philadelphia: Lippincott Williams \& Wilkins, 2006:2493. [ISBN 0781738946]

\section{Stone 1916}

Stone CA. Subluxation of the head of the radius. Journal of the American Medical Association 1916;67:28-9.

\section{CHARACTERISTICS OF STUDIES}

Characteristics of included studies [ordered by study ID]

\section{Teach 1996}

Teach SJ, Schutzman SA. Prospective study of recurrent radial head subluxation. Archives of Pediatrics \& Adolescent Medicine 1996;150(2):336-7.

\section{Thompson 2004}

Thompson GH. The upper limb. In: Behrman RE, Kliegman RM, Jensen HB editor(s). Nelson textbook of pediatrics. 17th Edition. Philadelphia: Saunders, 2004:2290.

\section{Vitello 2014}

Vitello S, Dvorkin R, Sattler S, Levy D, Ung L. Epidemiology of nursemaid's elbow. Western Journal of Emergency Medicine 2014;15(4):554-7.

\section{References to other published versions of this review Krul 2009}

Krul M, van der Wouden JC, van Suijlekom-Smit LWA, Koes BW. Manipulative interventions for reducing pulled elbow in young children. Cochrane Database of Systematic Reviews 2009, Issue 4. [DOI: 10.1002/14651858.CD007759.pub2]

\section{Krul 2012}

Krul M, van der Wouden JC, van Suijlekom-Smit LWA, Koes BW. Manipulative interventions for reducing pulled elbow in young children. Cochrane Database of Systematic Reviews 2012, Issue 1. [DOI: 10.1002/14651858.CD007759.pub3]

* Indicates the major publication for the study

\section{Asadi 2011}

\begin{tabular}{ll}
\hline Methods & Quasi-randomised clinical trial (according to date of birth). \\
\hline Participants & Orthopaedic emergency centre, Poorsina Hospital, Rasht, Iran. \\
& 2004 to 2009. \\
& Inclusion criteria: children less than 7 years old presenting with history and signs or symptoms of 'el- \\
& bow strain' (clinical diagnosis of radial head subluxation). \\
& Exclusion criteria: patients with doubtful or unknown history, history of direct trauma to elbow, specif- \\
& ic deformity, local oedema or swelling, ecchymosis on elbow, polytrauma, congenital bone disease. \\
& 110 children enrolled. \\
& 69 boys and 41 girls. \\
& Mean age 4.05 years (SD 1.51).
\end{tabular}

Interventions

Hyperpronation (figure provided showed elbow held at $90^{\circ}$ before hyperpronation at the wrist) $(n=52)$ versus 
Supination-flexion (figure provided showed elbow held at $90^{\circ}$ before supination at the wrist followed by flexion at the elbow) $(n=58)$.

If first attempt unsuccessful (extremity function had not returned), same method used for second attempt 15 minutes later. If this failed, the alternative method was used 15 minutes later. If unsuccessful, this was repeated after 15 minutes. If both methods failed, elbow radiography to rule out other injury.

\begin{tabular}{ll}
\hline Outcomes & Success after first attempt and second attempt (same method, 15 minutes later). \\
\hline Notes & Article in Persian Arabic with English abstract. \\
\hline
\end{tabular}

\section{Risk of bias}

\begin{tabular}{|c|c|c|}
\hline Bias & Authors' judgement & Support for judgement \\
\hline $\begin{array}{l}\text { Random sequence genera- } \\
\text { tion (selection bias) }\end{array}$ & High risk & Quasi-randomised (assignment according to odd and even birth date). \\
\hline $\begin{array}{l}\text { Allocation concealment } \\
\text { (selection bias) }\end{array}$ & High risk & Not concealed. \\
\hline $\begin{array}{l}\text { Blinding (performance } \\
\text { bias and detection bias) } \\
\text { All outcomes }\end{array}$ & High risk & $\begin{array}{l}\text { Participants: not possible. } \\
\text { Treatment provider: not possible. } \\
\text { Outcome assessor: unclear but probably not blinded. }\end{array}$ \\
\hline $\begin{array}{l}\text { Incomplete outcome data } \\
\text { (attrition bias) } \\
\text { All outcomes }\end{array}$ & Low risk & All 110 allocated children were included in the analysis. \\
\hline $\begin{array}{l}\text { Selective reporting (re- } \\
\text { porting bias) }\end{array}$ & Unclear risk & Unclear, no trial registration or protocol available. \\
\hline Other bias & Unclear risk & $\begin{array}{l}\text { No information regarding baseline comparability. Care providers and provi- } \\
\text { sion of treatment seem comparable.. }\end{array}$ \\
\hline
\end{tabular}

\section{Bek 2009}

\begin{tabular}{ll}
\hline Methods & Quasi-randomised trial (according to date of birth). \\
\hline Participants & $\begin{array}{l}\text { Accident and emergency department, Gülhane Military Medical Academy, Ankara, Turkey. } \\
\text { January to November } 2007 .\end{array}$ \\
& Inclusion criteria: aged younger than 5 years of age with a clinical presentation and history suggestive \\
of pulled elbow. & Exclusion criteria: earlier history of pulled elbow, marked deformity, local swelling and ecchymosis at \\
& elbow, and poly-traumatised patients. \\
& 66 children enrolled. \\
& 26 boys and 40 girls. \\
& Mean age 28.6 months (SD 11.2). \\
\hline Interventions & $\begin{array}{l}\left.\text { Hyperpronation: flexing the elbow to } 90^{\circ} \text { and rotating the forearm into hyperpronation ( } \mathrm{n}=34\right) \\
\text { versus } \\
\text { Supination-flexion: flexing the elbow to } 90^{\circ} \text { and rotating the forearm into supination followed by full } \\
\text { flexion of the elbow }(n=32) .\end{array}$
\end{tabular}


Bek 2009 (Continued)

If first attempt failed (child did not start to use injured arm), same method used for second attempt. If this failed, the alternative method was used.

\begin{tabular}{ll}
\hline Outcomes & Success rate during first attempt, second attempt (same method, 15 minutes later), and third method \\
(alternative method). & \\
Combined subjective rating by physician of difficulty of the manoeuvre; child's pain during reduction \\
and overall condition.
\end{tabular}

Notes All reductions carried out by one of three final-year residents, who received briefing about reduction methods before they started the study.

\section{Risk of bias}

\begin{tabular}{|c|c|c|}
\hline Bias & Authors' judgement & Support for judgement \\
\hline $\begin{array}{l}\text { Random sequence genera- } \\
\text { tion (selection bias) }\end{array}$ & High risk & Quasi-randomised (assignment according to odd and even birth date). \\
\hline $\begin{array}{l}\text { Allocation concealment } \\
\text { (selection bias) }\end{array}$ & High risk & Not concealed. \\
\hline $\begin{array}{l}\text { Blinding (performance } \\
\text { bias and detection bias) } \\
\text { All outcomes }\end{array}$ & High risk & $\begin{array}{l}\text { Participants: not possible. } \\
\text { Treatment provider: not possible. } \\
\text { Outcome assessor: unclear but probably not blinded. }\end{array}$ \\
\hline $\begin{array}{l}\text { Incomplete outcome data } \\
\text { (attrition bias) } \\
\text { All outcomes }\end{array}$ & Low risk & All 66 participants were included in the analysis. \\
\hline $\begin{array}{l}\text { Selective reporting (re- } \\
\text { porting bias) }\end{array}$ & Unclear risk & Unclear, no trial registration or protocol available. \\
\hline Other bias & Unclear risk & $\begin{array}{l}\text { Mean age in hyperpronation group was } 4 \text { months older, but the reported dif- } \\
\text { ference was not statistically significant }(P=0.1) \text {. Care providers and provision } \\
\text { of treatment seemed comparable. }\end{array}$ \\
\hline
\end{tabular}

Garcia-Mata 2014

\begin{tabular}{|c|c|}
\hline Methods & Quasi-randomised trial (odd or even days of hospital admission). \\
\hline \multirow[t]{7}{*}{ Participants } & Tertiary paediatric orthopaedic unit, Pamplona, Spain. \\
\hline & January 1996 to June 2012. \\
\hline & $\begin{array}{l}\text { Inclusion criteria: symptoms compatible with pulled elbow (causal mechanism, pseudoparalysis, posi- } \\
\text { tion of forearm). }\end{array}$ \\
\hline & $\begin{array}{l}\text { Exclusion criteria: underlying musculoskeletal disorder or condition, history of upper extremity injury, } \\
\text { or other systemic diagnosis. }\end{array}$ \\
\hline & $\begin{array}{l}115 \text { children enrolled. } \\
33 \text { boys and } 82 \text { girls. }\end{array}$ \\
\hline & Mean age: 27 months, range 20 to 64 months. \\
\hline & 30 children $(26 \%)$ reported a previous episode. \\
\hline
\end{tabular}


Garcia-Mata 2014 (Continued)

versus

Supination-flexion: complete flexion of the elbow simultaneous with forced supination of the forearm, while the thumb of the examiner was placed over the area of the radial head to detect a pop or click that confirmed diagnosis and reduction $(n=50)$.

If first attempt failed, the alternative manoeuvre was performed (waiting time unknown), if second attempt failed, first manoeuvre was repeated.

\begin{tabular}{|c|c|}
\hline Outcomes & Success at first attempt, at second attempt, and at third attempt. \\
\hline \multirow[t]{5}{*}{ Notes } & $\begin{array}{l}17 \text { ( } 8 \text { hyperpronation versus } 9 \text { supination-flexion) children had had attempts at reduction ( } 11 \text { had }>3 \\
\text { attempts) using the supination-flexion method before entering the study. These were not included in } \\
\text { the meta-analysis. }\end{array}$ \\
\hline & $\begin{array}{l}\text { Response from Serafín García-Mata on 6th April } 2017 \text { to queries from Helen Handoll; shared with au- } \\
\text { thors:: }\end{array}$ \\
\hline & $\begin{array}{l}\text { "1. The method of randomization: we choose HP or SF method depending on the number of the day: } \\
\text { even or odd number of the day, that the child attended. }\end{array}$ \\
\hline & 2. The method was the same throughout the 16 years. \\
\hline & 3. The 30 recurrent cases: we do not assess how many of them were of the HP or the SF groups." \\
\hline
\end{tabular}

\section{Risk of bias}

\begin{tabular}{lll}
\hline Bias & Authors' judgement & Support for judgement \\
\hline $\begin{array}{l}\text { Random sequence genera- } \\
\text { tion (selection bias) }\end{array}$ & High risk & $\begin{array}{l}\text { Vaguely described: "randomly choosing individuals and dividing patients into } \\
\text { 2 groups" in paper. Personal communication revealed assignment according } \\
\text { to day of admission (April 2017). }\end{array}$ \\
\hline $\begin{array}{l}\text { Allocation concealment } \\
\text { (selection bias) }\end{array}$ & High risk & $\begin{array}{l}\text { Not described in paper. Personal communication revealed assignment accord- } \\
\text { ing to day of admission (April 2017). }\end{array}$ \\
\hline $\begin{array}{l}\text { Blinding (performance } \\
\text { bias and detection bias) } \\
\text { All outcomes }\end{array}$ & High risk & $\begin{array}{l}\text { Participants: not possible. } \\
\text { Treatment provider: not possible. } \\
\text { Outcome assessor: unclear but probably not blinded. }\end{array}$ \\
\hline $\begin{array}{l}\text { Incomplete outcome data } \\
\text { (attrition bias) } \\
\text { All outcomes }\end{array}$ & Low risk & $\begin{array}{l}\text { No loss to follow-up. } \\
\text { Selective reporting (re- } \\
\text { porting bias) }\end{array}$ \\
\hline $\begin{array}{l}\text { Other bias } \\
\text { Unclear risk }\end{array}$ & $\begin{array}{l}\text { No trial registration or protocol available. } \\
\text { Unclear risk }\end{array}$ & $\begin{array}{l}\text { No baseline imbalances. Mean age in hyperpronation group was } 4 \text { months } \\
\text { younger, but the reported difference was not statistically significant }(P=0.68) . \\
\text { No data on distribution of children with a previous episode of pulled elbow. } \\
\text { Care providers and provision of treatment seemed comparable. }\end{array}$ \\
\hline
\end{tabular}

Green 2006

\begin{tabular}{ll}
\hline Methods & Randomised trial. \\
\hline Participants & Emergency department, Miami Children's Hospital, Miami, Florida, USA. \\
& March 2003 to January 2004.
\end{tabular}


Green 2006 (Continued)

Inclusion criteria: aged between 6 months and 7 years with clinical findings suggestive of radial head subluxation.

Exclusion criteria: evidence of bony tenderness or swelling.

75 children enrolled, of whom 3 (allocated group not stated) were excluded due to nonadherence to protocol ( 1 data form was lost; and 2 were excluded because their study packets were completed by residents and not by the attending physician).

29 boys and 41 girls. (As well as the 3 exclusions, Table 1 of the article had 2 missing; see Notes). Mean age 26.8 months.

\begin{tabular}{|c|c|}
\hline Interventions & $\begin{array}{l}\text { Forced pronation without flexion }(n=35) \\
\text { versus } \\
\text { Supination-flexion ( } n=37) \text {. } \\
\text { If primary attempt was unsuccessful, the alternative method was used for the second attempt } 10 \text { min- } \\
\text { utes later. If still unsuccessful, the participant received care at discretion of the attending physician. }\end{array}$ \\
\hline Outcomes & $\begin{array}{l}\text { Success rate during first attempt and second attempt (with the alternative method), which was done } 10 \\
\text { minutes later. } \\
\text { Pain before, during and } 1 \text { minute after successful repositioning using visual analogue scale }(10 \mathrm{~cm}) \text { by } \\
\text { parents, nurse and physician. (For pain measurement, } 9 \text { additional children were excluded due to un- } \\
\text { successful first attempt of reduction). }\end{array}$ \\
\hline Notes & $\begin{array}{l}\text { Number of participants in flow chart and text did not match with table of baseline characteristics in the } \\
\text { paper. The former were assumed to be correct. }\end{array}$ \\
\hline
\end{tabular}

\section{Risk of bias}

\begin{tabular}{|c|c|c|}
\hline Bias & Authors' judgement & Support for judgement \\
\hline $\begin{array}{l}\text { Random sequence genera- } \\
\text { tion (selection bias) }\end{array}$ & Unclear risk & "Randomly assigned using a consecutive case allocation" (p.235). \\
\hline $\begin{array}{l}\text { Allocation concealment } \\
\text { (selection bias) }\end{array}$ & Unclear risk & Not reported. \\
\hline $\begin{array}{l}\text { Blinding (performance } \\
\text { bias and detection bias) } \\
\text { All outcomes }\end{array}$ & High risk & $\begin{array}{l}\text { Participants: not possible. } \\
\text { Treatment provider: not possible. } \\
\text { Outcome assessor: unclear but probably not blinded. }\end{array}$ \\
\hline $\begin{array}{l}\text { Incomplete outcome data } \\
\text { (attrition bias) } \\
\text { All outcomes }\end{array}$ & Unclear risk & $\begin{array}{l}\text { Table } 1 \text { was not clear (data discrepancies in the article); } 3 \text { excluded partici- } \\
\text { pants (non adherence to study protocol) with no data. }\end{array}$ \\
\hline $\begin{array}{l}\text { Selective reporting (re- } \\
\text { porting bias) }\end{array}$ & High risk & $\begin{array}{l}\text { No trial registration or protocol available. Pain perception reported for suc- } \\
\text { cessful reduction only. }\end{array}$ \\
\hline Other bias & High risk & $\begin{array}{l}\text { Considerable baseline imbalance with respect to time since injury (mean time } \\
\text { of injury: } 6.58 \text { versus } 13.47 \text { hours) probably due to outlier(s) (high SD). Care } \\
\text { providers and provision of treatment seemed comparable. }\end{array}$ \\
\hline
\end{tabular}


Gunaydin 2013

\begin{tabular}{|c|c|}
\hline Methods & Quasi-randomised (according to day of admission). \\
\hline \multirow[t]{6}{*}{ Participants } & Tertiary care emergency department, Ankara, Turkey. \\
\hline & October 2009 to October 2010. \\
\hline & Inclusion criteria: age 0 to 6 years, written consent, 'nursemaid's elbow'. \\
\hline & Exclusion criteria: localised elbow oedema, ecchymosis, deformity, fracture findings on x-ray. \\
\hline & $\begin{array}{l}150 \text { children enrolled. } \\
51 \text { boys and } 99 \text { girls. }\end{array}$ \\
\hline & Mean age 27.5 months, range 6 to 72 months. \\
\hline \multirow[t]{3}{*}{ Interventions } & $\begin{array}{l}\text { Hyperpronation: child's elbow held at } 90^{\circ} \text { in one hand and then firmly pronating wrist }(n=68) \\
\text { versus }\end{array}$ \\
\hline & $\begin{array}{l}\text { Supination-flexion: performed by holding the child's elbow at } 90^{\circ} \text { with one hand, then firmly supinating } \\
\text { the wrist, and by flexing the elbow so that the wrist was directed to the ipsilateral shoulder }(n=82) \text {. }\end{array}$ \\
\hline & $\begin{array}{l}\text { If first attempt unsuccessful (child did not reach for a toy or piece of candy within } 10 \text { minutes), after an- } \\
\text { other } 10 \text { minutes a second attempt was made with same technique. If second attempt unsuccessful, } \\
\text { the other technique was used. }\end{array}$ \\
\hline
\end{tabular}

\section{Outcomes}

Success after first attempt, second attempt, third attempt, total.

Pain (in 113 children who were older than 1 year and had a successful first attempt) using the mCHEOPS (modified Children's Hospital of Eastern Ontario Pain Scale).

\section{Notes}

\section{Risk of bias}

\begin{tabular}{|c|c|c|}
\hline Bias & Authors' judgement & Support for judgement \\
\hline $\begin{array}{l}\text { Random sequence genera- } \\
\text { tion (selection bias) }\end{array}$ & High risk & "pseudorandomized ... according to date of admission to ED": \\
\hline $\begin{array}{l}\text { Allocation concealment } \\
\text { (selection bias) }\end{array}$ & High risk & No concealment. \\
\hline $\begin{array}{l}\text { Blinding (performance } \\
\text { bias and detection bias) } \\
\text { All outcomes }\end{array}$ & High risk & $\begin{array}{l}\text { Participants: not possible. } \\
\text { Treatment provider: not possible. } \\
\text { Outcome assessor: unclear but probably not blinded. }\end{array}$ \\
\hline $\begin{array}{l}\text { Incomplete outcome data } \\
\text { (attrition bias) } \\
\text { All outcomes }\end{array}$ & Low risk & No loss to follow-up. \\
\hline $\begin{array}{l}\text { Selective reporting (re- } \\
\text { porting bias) }\end{array}$ & Unclear risk & No trial registration or protocol available. \\
\hline Other bias & Unclear risk & $\begin{array}{l}\text { The sex data in Table } 1 \text { in the article were incorrect; they reported data for } 91 \\
\text { and } 59 \text { participants in the two groups. Care providers and provision of treat- } \\
\text { ment seemed comparable. }\end{array}$ \\
\hline
\end{tabular}


Guzel 2014

\begin{tabular}{|c|c|}
\hline Methods & Randomised trial. \\
\hline Participants & $\begin{array}{l}\text { Emergency department of Samsun Training and Research Hospital, Turkey. } \\
\text { June } 2011 \text { to March } 2012 \text {. } \\
\text { Inclusion criteria: previously healthy children younger than } 6 \text { years, presenting with clinical findings } \\
\text { suggestive of radial head subluxation (difficulty in moving elbow and painful pronation). } \\
\text { Exclusion criteria: fracture, point tenderness, local ecchymosis (bruising) or oedema (swelling), defor- } \\
\text { mity and persistent pain. } \\
78 \text { children enrolled ( } 40 \text { to hyperpronation, } 38 \text { to supination) (but see Notes below). } \\
\text { (Of 78) } 31 \text { boys and } 47 \text { girls. } \\
\text { Mean age: } 30 \text { months, range } 9 \text { to } 60 \text { months. }\end{array}$ \\
\hline Outcomes & $\begin{array}{l}\text { Success rate during first attempt (success was return to baseline function of the arm after } 20 \text { minutes), } \\
\text { second attempt (same method, } 10 \text { minutes later), and third attempt (alternative method, } 15 \text { minutes } \\
\text { later); need for latter was considered a 'failed reduction'. (However, two complete failures were exclud- } \\
\text { ed from the results). } \\
\text { Pain before and after reduction: if child was able to communicate: faces rating scale (WBFPRS); if not: } \\
\text { Face, Legs, Activity, Cry, Consolability Scale (FLACCS) scored by research assistant. }\end{array}$ \\
\hline Notes & $\begin{array}{l}\text { Badly edited paper with multiple errors and typos. Number of participants unclear: } 88 \text { mentioned un- } \\
\text { der study design and sum of people with different mechanism of injuries at end of results, but Tables } \\
1 \text { and } 3 \text { gave } n=78 \text {, and start of results paragraph was confusing. Table } 1 \text { gave baseline characteristics } \\
\text { and also study results. }\end{array}$ \\
\hline
\end{tabular}

\section{Risk of bias}

\begin{tabular}{|c|c|c|}
\hline Bias & Authors' judgement & Support for judgement \\
\hline $\begin{array}{l}\text { Random sequence genera- } \\
\text { tion (selection bias) }\end{array}$ & Low risk & "via a randomizations table". \\
\hline $\begin{array}{l}\text { Allocation concealment } \\
\text { (selection bias) }\end{array}$ & Unclear risk & Not described. \\
\hline $\begin{array}{l}\text { Blinding (performance } \\
\text { bias and detection bias) } \\
\text { All outcomes }\end{array}$ & High risk & $\begin{array}{l}\text { Participants: not possible. } \\
\text { Treatment provider: not possible. } \\
\text { Outcome assessor not blinded. }\end{array}$ \\
\hline $\begin{array}{l}\text { Incomplete outcome data } \\
\text { (attrition bias) } \\
\text { All outcomes }\end{array}$ & Unclear risk & $\begin{array}{l}\text { No loss to follow-up but postrandomisation exclusions may have affected re- } \\
\text { sults. }\end{array}$ \\
\hline $\begin{array}{l}\text { Selective reporting (re- } \\
\text { porting bias) }\end{array}$ & Unclear risk & No trial registration or protocol available. \\
\hline
\end{tabular}


Guzel 2014 (Continued)

Other bias

High risk
Median age in supination group 4 months older, no statistical testing done or possible.

Poor reporting was likely to indicate other problems with this trial. Care providers and provision of treatment seemed comparable.

Macias 1998

\begin{tabular}{|c|c|}
\hline Methods & Randomised trial. \\
\hline \multirow[t]{5}{*}{ Participants } & $\begin{array}{l}\text { Two urban paediatric emergency departments and two suburban paediatric ambulatory care centres } \\
\text { in the USA (Texas and Colorado). } \\
\text { June } 1996 \text { to May } 1997 .\end{array}$ \\
\hline & $\begin{array}{l}\text { Inclusion criteria: previously healthy, younger than } 6 \text { years with clinical findings suggestive of radial } \\
\text { head subluxation. } \\
\text { Exclusion criteria: point tenderness, local areas of ecchymosis (bruising) or oedema (swelling), defor- } \\
\text { mity and persistent pain. }\end{array}$ \\
\hline & $\begin{array}{l}90 \text { episodes (in } 85 \text { participants) were included in randomisation, five were excluded because of a frac- } \\
\text { ture, and one participant failed protocol. }\end{array}$ \\
\hline & $\begin{array}{l}34 \text { boys and } 51 \text { girls. } \\
\text { Mean age } 27.7 \text { months, range } 2 \text { to } 68 \text { months. }\end{array}$ \\
\hline & $28(33 \%)$ reported a previous episode. \\
\hline \multirow[t]{4}{*}{ Interventions } & $\begin{array}{l}\text { Hyperpronation: the child's elbow was gripped while held at } 90^{\circ} \text { in one hand while forcefully pronating } \\
\text { the wrist with the other hand (picture provided) }(n=41)\end{array}$ \\
\hline & versus \\
\hline & $\begin{array}{l}\text { Supination-flexion: child's elbow gripped in one hand while the elbow was held at } 90^{\circ} \text { and the wrist } \\
\text { forcefully supinated with the other hand (picture provided) }(n=44) \text {. }\end{array}$ \\
\hline & $\begin{array}{l}\text { Participants were reexamined every } 5 \text { minutes throughout protocol for return of elbow function. Initial } \\
\text { procedure repeated if no return of baseline function at } 15 \text { minutes. If failure of second attempt after } 15 \\
\text { minutes, third attempt using alternative technique (cross-over); fourth attempt also used alternative } \\
\text { technique. Continued failure was followed by radiography of the elbow and treatment at discretion of } \\
\text { emergency medicine physician. }\end{array}$ \\
\hline
\end{tabular}

Outcomes

Success rate (success was return to baseline function of the arm after 15 minutes) at first attempt, second attempt with same procedure or third (and fourth) attempt with the other procedure.

Notes

Five participants enrolled twice (in 4 participants, the episodes were more than 2 months apart and 1 participant presented after several days of normal usage of the arm), not accounted for clustering in analysis.

\section{Risk of bias}

\begin{tabular}{lll}
\hline Bias & Authors' judgement & Support for judgement \\
\hline $\begin{array}{l}\text { Random sequence genera- } \\
\text { tion (selection bias) }\end{array}$ & Low risk & $\begin{array}{l}\text { "Enrollees were randomly assigned to begin the protocol with either the hy- } \\
\text { perpronation technique or the supination technique via a randomizations ta- } \\
\text { ble." }\end{array}$ \\
\hline $\begin{array}{l}\text { Allocation concealment } \\
\text { (selection bias) }\end{array}$ & Low risk & $\begin{array}{l}\text { "Technique assignment was unknown to the attending physician at the time of } \\
\text { enrolment". }\end{array}$ \\
\hline
\end{tabular}


Macias 1998 (Continued)
Blinding (performance
High risk
Participants: not possible.
bias and detection bias)
Treatment provider: not possible.
All outcomes
Outcome assessor: unclear but probably not blinded.

Incomplete outcome data Low risk Data for all 90 participants were reported.
(attrition bias)
All outcomes

\begin{tabular}{lll}
\hline $\begin{array}{l}\text { Selective reporting (re- } \\
\text { porting bias) }\end{array}$ & Unclear risk & No trial registration or protocol available. \\
\hline Other bias & Unclear risk & $\begin{array}{l}\text { No baseline imbalance but data only reported for } 85, \text { not } 90 \text { participants. Care } \\
\text { providers and provision of treatment seemed comparable. }\end{array}$ \\
\hline
\end{tabular}

McDonald 1999

\begin{tabular}{|c|c|}
\hline Methods & Randomised trial. \\
\hline \multirow[t]{5}{*}{ Participants } & $\begin{array}{l}\text { Emergency department of a tertiary care children's hospital in Louisville, USA. } \\
\text { July } 1996 \text { to December } 1997 .\end{array}$ \\
\hline & $\begin{array}{l}\text { Inclusion criteria: children younger than } 7 \text { years presenting with a complaint of an upper extremity in- } \\
\text { jury and with refusal to use their arm. } \\
\text { Exclusion criteria: history of neurologic impairment, congenital bony malformation, oedema or obvi- } \\
\text { ous bony deformity. }\end{array}$ \\
\hline & $\begin{array}{l}148 \text { participants enrolled, of whom } 13 \text { were excluded: } 6 \text { had a fracture; } 2 \text { spontaneously reduced; in } 2 \\
\text { cases, the study protocol was not followed; and in } 3 \text { cases data were missing. }\end{array}$ \\
\hline & 58 boys and 77 girls. \\
\hline & Age range: 3 months to 6 years. \\
\hline
\end{tabular}

Interventions $\quad$ Rapid hyperpronation and flexion $(\mathrm{n}=67)$

versus

Rapid supination and flexion $(n=68)$.

If failure (child unable to use his/her arm to reach for a toy or piece of candy within 30 minutes after manipulation) after first attempt, second attempt used same procedure and third attempt used the other procedure.

Outcomes Success rate (success was defined as using the arm to reach for a toy or piece of candy within 30 minutes after manipulation) after first attempt. If failed, second attempt used same procedure and third attempt used the other procedure.

Pain during manipulation measured by the physician and the parent on an ordinal scale $(0=$ no pain, 1 $=$ little pain, 2 = quite a lot of pain, 3 = very bad pain).

Parents' scoring sheets were illustrated with descriptive drawings of facial expressions.

Notes

Prior to the start of the study, physicians received a brief in-service training on performing both reduction techniques. Printed instructions given on enrolment forms. Reductions were performed by students or residents (trainees).

\section{Risk of bias}


MCDonald 1999 (Continued)

\begin{tabular}{|c|c|c|}
\hline Bias & Authors' judgement & Support for judgement \\
\hline $\begin{array}{l}\text { Random sequence genera- } \\
\text { tion (selection bias) }\end{array}$ & Low risk & $\begin{array}{l}\text { ".. blocked randomisation list generated by computer... trial was balanced af- } \\
\text { ter every } 10 \text { patients". }\end{array}$ \\
\hline $\begin{array}{l}\text { Allocation concealment } \\
\text { (selection bias) }\end{array}$ & Unclear risk & Not reported. \\
\hline $\begin{array}{l}\text { Blinding (performance } \\
\text { bias and detection bias) } \\
\text { All outcomes }\end{array}$ & High risk & $\begin{array}{l}\text { Participants: not possible. } \\
\text { Treatment provider: not possible. } \\
\text { Outcome assessor: unclear but probably not. }\end{array}$ \\
\hline $\begin{array}{l}\text { Incomplete outcome data } \\
\text { (attrition bias) } \\
\text { All outcomes }\end{array}$ & Low risk & $\begin{array}{l}\text { Low risk for primary outcome. Unclear for pain assessments: three partici- } \\
\text { pants missing in pronation group. }\end{array}$ \\
\hline $\begin{array}{l}\text { Selective reporting (re- } \\
\text { porting bias) }\end{array}$ & Unclear risk & No trial registration or protocol available. \\
\hline Other bias & Low risk & $\begin{array}{l}\text { No important baseline imbalance. Care providers and provision of treatment } \\
\text { seemed comparable. }\end{array}$ \\
\hline
\end{tabular}

Schunk 1990

Methods Quasi-randomised trial (odd or even days of hospital admission).

\section{Participants}

Emergency department of a children's hospital in Los Angeles, USA.

During a nine-month period in the 1980s.

Inclusion criteria: "all children who were diagnosed as having a radial head subluxation at discharge".

Exclusion criteria: none.

83 children with 87 episodes, 1 child with both arms affected.

36 boys and 51 girls (based on 87 episodes).

Mean age 27 months, range 4.5 to 73 months.

$26.7 \%$ reported a previous episode; however, this did not tally with the number of children with recurrent episodes; stated to be 19.

versus

Supination of wrist, then elbow flexed $(n=51)$.

If first attempt failed (child failed to regain use of his or her arm) after 15 minutes, the other manoeuvre was tried. Obtaining radiographs or orthopaedic consultation were optional. Radiographs recommended if two reduction attempts failed or there was diagnostic uncertainty.

Outcomes Success after first maneuver and after second maneuver (waiting time 15 minutes).

\section{Notes}

\section{Risk of bias}


Schunk 1990 (Continued)

Random sequence genera- High risk Quasi-randomised: allocation according to odd and even days of admission. tion (selection bias)

\begin{tabular}{ll}
\hline $\begin{array}{l}\text { Allocation concealment } \\
\text { (selection bias) }\end{array}$ & High risk concealment.
\end{tabular}

\begin{tabular}{lll}
\hline $\begin{array}{l}\text { Blinding (performance } \\
\text { bias and detection bias) } \\
\text { All outcomes }\end{array}$ & High risk & $\begin{array}{l}\text { Participants: not possible. } \\
\text { Treatment provider: not possible. } \\
\text { Outcome assessor: not blinded. }\end{array}$ \\
\hline $\begin{array}{l}\text { Incomplete outcome data } \\
\text { (attrition bias) } \\
\text { All outcomes }\end{array}$ & Unclear risk & $\begin{array}{l}\text { For episodes treated according to protocol, but data for second attempts not } \\
\text { provided. }\end{array}$ \\
\hline $\begin{array}{l}\text { Selective reporting (re- } \\
\text { porting bias) }\end{array}$ & Unclear risk & No trial registration or protocol available. \\
\hline $\begin{array}{l}\text { Other bias } \\
\text { High risk }\end{array}$ & $\begin{array}{l}\text { Unknown number of cases not treated according to protocol, due to physician } \\
\text { preference for supination-flexion, resulting in skewed distribution (25 exten- } \\
\text { sion versus } 51 \text { flexion). }\end{array}$ \\
& $\begin{array}{l}\text { Additionally,11/87 episodes could not be evaluated because another method } \\
\text { was used or cases resolved spontaneously. }\end{array}$ \\
\hline
\end{tabular}

\author{
SD: standard deviation \\ HP: hyperpronation \\ SF: supination-flexion \\ ED: emergency department \\ mCHEOPS: modified Children's Hospital of Eastern Ontario Pain Scale \\ WBFPRS: Wong-Baker Faces Pain Rating Scale \\ FLACCS: Faces, Legs, Activities, Cry Consolability Scale
}

Characteristics of excluded studies [ordered by study ID]

\begin{tabular}{ll}
\hline Study & Reason for exclusion \\
\hline Dixon 2014 & $\begin{array}{l}\text { Randomised trial which compared trained nurses performing hyperpronation to physicians per- } \\
\text { forming their favourite technique. This was not a comparison of manipulative interventions. }\end{array}$ \\
\hline Quan 1985 & Neither randomised nor quasi-randomised. Unclear how choice between treatments was made. \\
\hline Ruffing 2014 & $\begin{array}{l}\text { Not comparing methods, but participant series }(\mathrm{n}=41) \text { of one method, a modified pronation tech- } \\
\text { nique. }\end{array}$ \\
\hline Taha 2000 & $\begin{array}{l}\text { Not investigating methods to reduce the pulled elbow, but about subsequent management, includ- } \\
\text { ing splinting. Not in scope of review. }\end{array}$ \\
\hline
\end{tabular}

Characteristics of studies awaiting assessment [ordered by study ID]

Vidosavljevic 2006

\begin{tabular}{ll}
\hline Methods & An eligible comparison but unclear if actually "randomized" as claimed. \\
\hline Participants & Emergency department of University Children's Hospital of Belgrade, Serbia.
\end{tabular}


Vidosavljevic 2006 (Continued)

July 2004 to October 2004.

54 children less than 4 years old with pulled elbow.

\begin{tabular}{ll}
\hline Interventions & Hyperpronation versus supination-flexion. \\
\hline Outcomes & $\begin{array}{l}\text { Success evaluated by time to return to function, duration of child crying and palpable confirmation } \\
\text { of successful reduction. Failure was another attempt using the other method because of non-re- } \\
\text { turn of full function after } 30 \text { minutes. }\end{array}$ \\
\hline
\end{tabular}

Notes

This trial was only reported as a conference abstract. The trial authors referred to "preliminary results". A request for further information has been sent.

Characteristics of ongoing studies [ordered by study ID]

NCT01562535

\begin{tabular}{ll}
\hline Trial name or title & A clinical trial of pronation versus supination maneuvers for the reduction of the pulled elbow. \\
\hline Methods & Randomised, single-blind, trial. \\
\hline Participants & Target: 90 children aged 6 months to 6 years. \\
Inclusion criteria: Pulled elbow suspected in any child presenting one of the following: \\
- History of an adult or bigger person that had pulled the child's elbow non-intentionally; \\
- Presence of intense pain at the arrival at the emergency department and unwilling to move the \\
arm. \\
Exclusion criteria: \\
- Any suspicion of injury that could be intentional (child abuse); \\
- Any suspicion of child suffering a possible fracture (the mechanism of the injury was not from \\
pulling the child's arm, the arm presented obvious deformity, ecchymoses, oedema, etc.); \\
- The mechanism was from multiple trauma; \\
Any chronic disease affecting the adequate bone mineralization (vitamin D deficiency, osteogen-
\end{tabular}

\begin{tabular}{ll}
\hline Interventions & Pronation versus supination. \\
\hline Outcomes & Successful reduction (10 to 20 minutes). \\
& Pain of the procedure (1 to 5 minutes). \\
\hline Starting date & June 2012 (see Notes). \\
\hline Contact information & Carlos A Cuello-Garcia, Instituto Tecnologico y de Estudios Superiores de Monterey, Mexico, \\
& email: carlos.cuello@itesm.mx. \\
\hline Notes & Email contact with Cuello-Garcia (September 2014): study not started yet. Cuelle-Garcia moved to \\
Canada, former colleague plans to continue.
\end{tabular}


DATA AND ANALYSES

Comparison 1. Pronation versus supination

\begin{tabular}{lllll}
\hline Outcome or subgroup title & No. of studies & $\begin{array}{l}\text { No. of partici- } \\
\text { pants }\end{array}$ & Statistical method & Effect size \\
\hline $\begin{array}{llll}1 \text { Failure: second attempt required } \\
\text { 2 Failure: continued failure after second }\end{array}$ & 8 & 811 & $\begin{array}{l}\text { Risk Ratio (M-H, Fixed, } \\
95 \% \mathrm{Cl})\end{array}$ & $0.35[0.25,0.50]$ \\
\hline \begin{tabular}{l} 
attempt with same procedure \\
\hline
\end{tabular} & 6 & 624 & $\begin{array}{l}\text { Risk Ratio (M-H, Fixed, } \\
95 \% \mathrm{Cl})\end{array}$ & $0.16[0.09,0.32]$ \\
\hline
\end{tabular}

Analysis 1.1. Comparison 1 Pronation versus supination, Outcome 1 Failure: second attempt required.

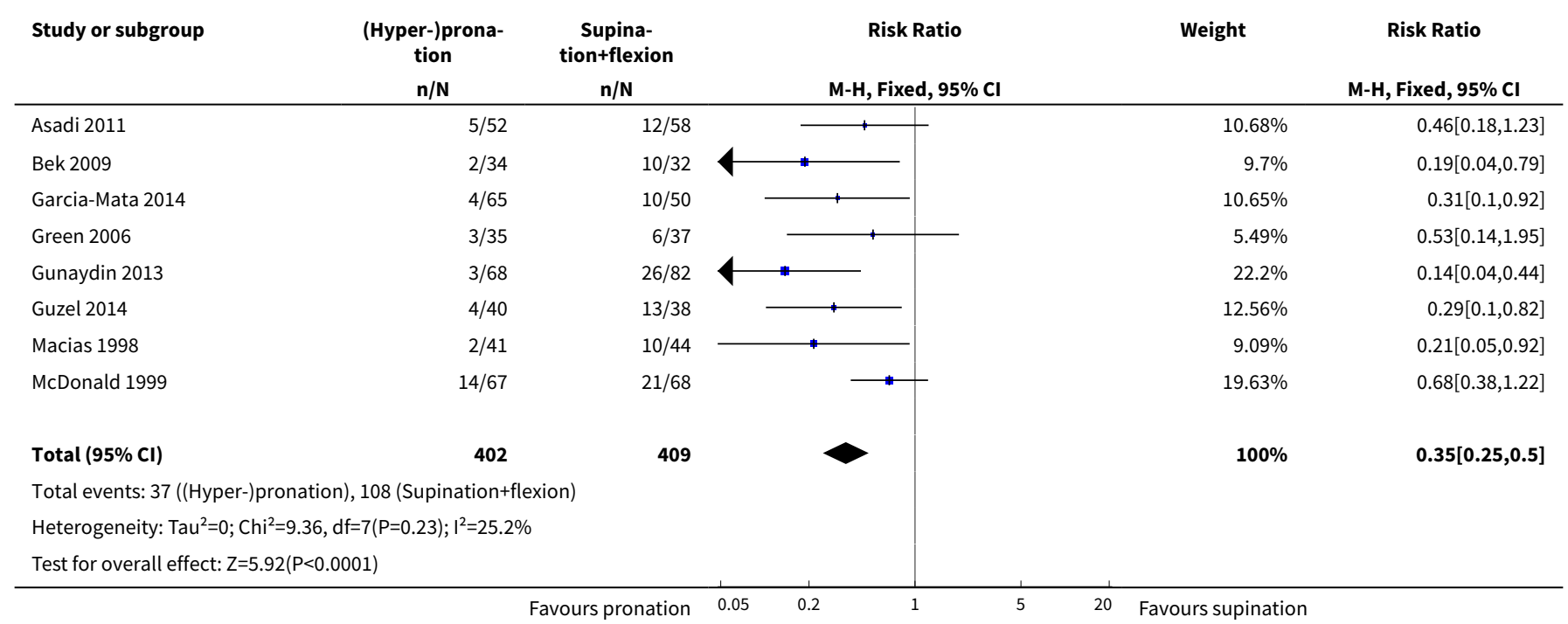

Analysis 1.2. Comparison 1 Pronation versus supination, Outcome 2 Failure: continued failure after second attempt with same procedure.

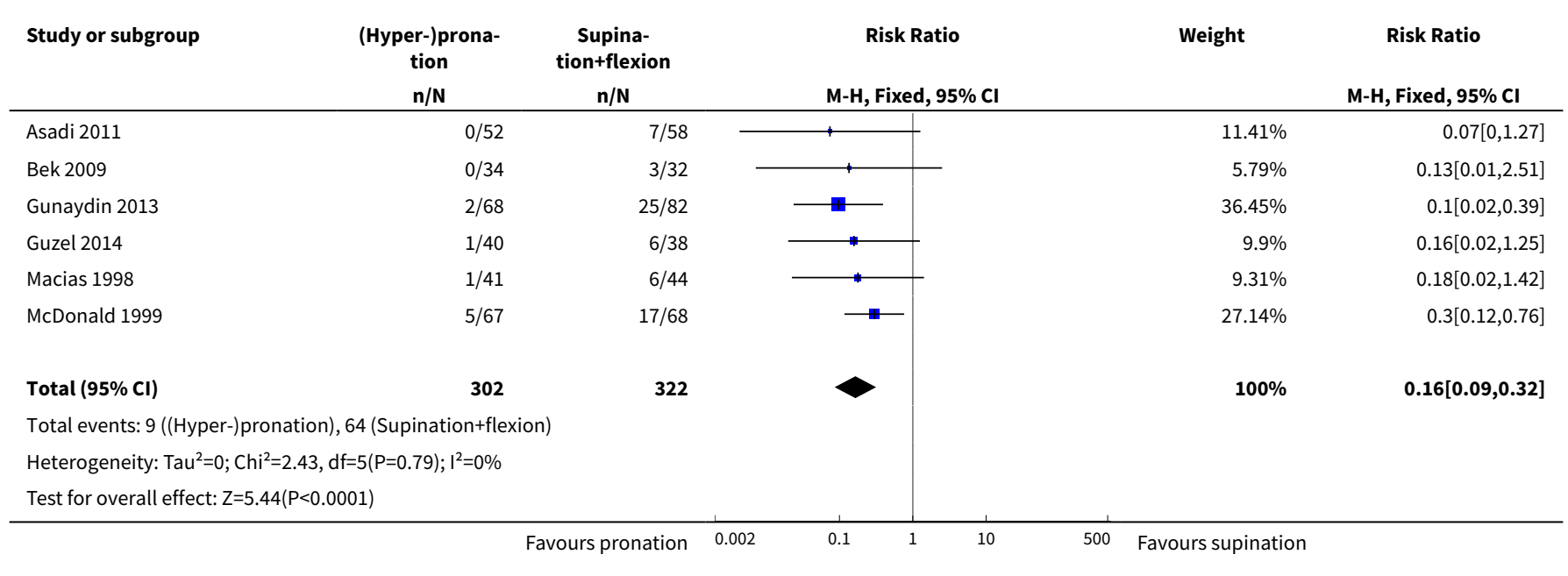


Comparison 2. Supination and extension versus supination then flexion

\begin{tabular}{lllll}
\hline Outcome or subgroup title & No. of studies & $\begin{array}{l}\text { No. of partici- } \\
\text { pants }\end{array}$ & Statistical method & Effect size \\
\hline 1 Failure: second attempt required & 1 & & Risk Ratio (M-H, Fixed, 95\% Cl) & $\begin{array}{l}\text { Totals not select- } \\
\text { ed }\end{array}$ \\
\hline
\end{tabular}

Analysis 2.1. Comparison 2 Supination and extension versus supination then flexion, Outcome 1 Failure: second attempt required.

\begin{tabular}{|c|c|c|c|c|c|c|}
\hline \multirow{2}{*}{$\begin{array}{l}\text { Study or subgroup } \\
\text { Schunk } 1990\end{array}$} & $\begin{array}{c}\text { Supination + extension } \\
n / N \\
\end{array}$ & $\begin{array}{c}\text { Supination + flexion } \\
\mathrm{n} / \mathrm{N}\end{array}$ & \multicolumn{3}{|c|}{$\begin{array}{c}\text { Risk Ratio } \\
\text { M-H, Fixed, 95\% Cl }\end{array}$} & \multirow{2}{*}{$\begin{array}{c}\text { Risk Ratio } \\
\text { M-H, Fixed, 95\% Cl } \\
1.63[0.74,3.62]\end{array}$} \\
\hline & $8 / 25$ & $10 / 51$ & & & \begin{tabular}{l|l} 
& 1
\end{tabular} & \\
\hline
\end{tabular}

\section{ADDITIONAL TABLES}

Table 1. Synonyms for 'pulled elbow' found in the literature (adapted from Krul 2011)

Radial head subluxation

Partial dislocation of the radial head peculiar to children

Dislocation of the head of the radius by elongation

Annular ligament displacement

Partial epiphyseal separation of the radial head

Anterior isolated subluxation of the radial head

Internal derangement of the elbow

Slipped elbow of young children

Painful elongation of young children

Painful paralysis in young children

Rotation syndrome

Painful pronation

Tamper tantrum elbow

Elbow sprain

Goyrands's injury 
Table 1. Synonyms for 'pulled elbow' found in the literature (adapted from Krul 2011) (Continued)

Malaigne's luxation

Gromeyer's injury

Pronatio dolorosa infantum (Chassaignac)

Curbstone fracture

Supermarket elbow

Sunday (afternoon) arm

Housemaid's elbow

Nursemaid's elbow

Babysitter's elbow

Table 2. Sensitivity analyses: Pronation versus supination: treatment failure at first attempt

\begin{tabular}{|c|c|c|}
\hline Sensitivity analysis & Results & NNT \\
\hline $\begin{array}{l}\text { Removal of quasi-RCTs } \\
\text { Asadi 2011; Bek 2009; Garcia-Mata 2014; Gunaydin } 2013\end{array}$ & $\begin{array}{l}\text { RR } 0.47,95 \% \mathrm{Cl} 0.30 \text { to } 0.73 ; 370 \text { participants; } \\
\mathrm{I}^{2}=13 \%\end{array}$ & $8,95 \% \mathrm{Cl} 5$ to 17 \\
\hline $\begin{array}{l}\text { Removal of Green } 2006 \\
\text { (baseline imbalance) }\end{array}$ & $\begin{array}{l}\text { RR } 0.34,95 \% \mathrm{Cl} 0.24 \text { to } 0.49 ; 739 \text { participants; } \\
\mathrm{I}^{2}=35 \%\end{array}$ & $6,95 \% \mathrm{Cl} 5$ to 8 \\
\hline $\begin{array}{l}\text { Removal of } 17 \text { participants with prior } \\
\text { manipulation in Garcia-Mata 2014) }\end{array}$ & $\begin{array}{l}\text { RR } 0.35,95 \% \mathrm{Cl} 0.24 \text { to } 0.50 ; 794 \text { participants; } \\
\mathrm{I}^{2}=28 \%\end{array}$ & $7,95 \% \mathrm{Cl} 5$ to 10 \\
\hline
\end{tabular}

Table 3. Pronation versus supination trials: ultimate failure

\begin{tabular}{llll}
\hline Study & Outcome definition & $\begin{array}{c}\text { Overall no. of fail- } \\
\text { ures / no. episodes }\end{array}$ & Protocol \\
\hline Asadi 2011 & Failure after 4 attempts & Not reported & 4 attempts, \\
& & cross-over on 3rd attempt \\
\hline Bek 2009 & Failure after 3 attempts & $0 / 66(0 \%)$ & 3 attempts, \\
& & & cross-over on 3rd attempt \\
\hline Garcia-Mata 2014 & Failure after 3 attempts & $3 / 115(2.6 \%)$ & 3 attempts, \\
& & & cross-over on 2rd attempt \\
& & original method for 3rd attempt
\end{tabular}


Table 3. Pronation versus supination trials: ultimate failure (Continued)

cross-over on 2nd attempt

\begin{tabular}{llll}
\hline Gunaydin 2013 & Failure after 3 attempts & $0 / 150(0 \%)$ & 3 attempts, \\
& & cross-over on 3rd attempt \\
\hline Guzel 2014 & Failure after 3 attempts & Not reported & 3 attempts, \\
& Failure after 4 attempts & $1 / 90(1.1 \%)$ & cross-over on 3rd attempt \\
\hline Macias 1998 & & cross-over on 3rd attempt \\
& Failure after 3 attempts & $6 / 148(4.1 \%)$ & order same for 4th attempt \\
\hline McDonald 1999 & & cross-over on 3rd attempt \\
\hline
\end{tabular}

\section{APPENDICES}

\section{Appendix 1. Search strategies for this update (2011 to September 2016)}

\section{CENTRAL (Wiley Online Library)}

\#1 MeSH descriptor: [Elbow Joint] this term only (231)

\#2 MeSH descriptor: [Elbow] this term only (164)

\#3 elbow:ti,ab,kw (1970)

\#4 radial or radius:ti,ab,kw AND head or distal:ti,ab,kw (1077)

\#5 \#1 or \#2 or \#3 or \#4 (2976)

\#6 MeSH descriptor: [Dislocations] this term only (249)

\#7 dislocate* or slipped or pulled or sublux* or "internal derangement" or "painful pronation" or "nternal ly deranged":ti,ab,kw (542)

\#8 \#6 or \#7 (741)

\#9 \#5 and \#8 (52)

\#10 "Goyrand's injury" or "Malaigne's luxation" or "nursemaid's elbow" or "Babysitter's elbow" or "Temper tantrum elbow" or "Sunday afternoon arm" or "Gromeyer's injury" or "curbstone fracture" or "supermarket elbow" or "pronatio dolorosa infantum" or "annular ligament displacement":ti,ab,kw (5)

\#11 \#9 or \#10 (53)

\#12 MeSH descriptor: [Child] explode all trees (192)

\#13 MeSH descriptor: [Infant] explode all trees (14574)

\#14 MeSH descriptor: [Pediatrics] explode all trees (631)

\#15 MeSH descriptor: [Adolescent] explode all trees (86589)

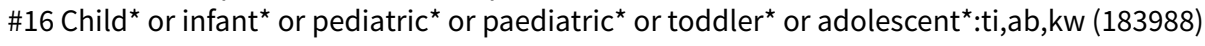

$\# 17 \# 12$ or \#13 or \#14 or \#15 or \#16 (183999)

$\# 18 \# 11$ and \#17 (29)

\section{MEDLINE (Ovid Online)}

1 Elbow/ or Elbow Joint/ (16286)

2 elbow.tw. (25196)

3 ((radial or radius) and (head or distal)).tw. (16595)

41 or 2 or $3(44533)$

5 Dislocations/ (23028)

6 (dislocate* or slipped or pulled or sublux ${ }^{\star}$ or internal derangement or painful pronation or internally deranged).tw. (23546)

75 or $6(42780)$

84 and 7 (3427)

9 (Goyrand* injury or Malaigne* luxation or nursemaid* elbow or Babysitter* elbow or Temper tantrum elbow or Sunday afternoon arm or Gromeyer* injury or curbstone fracture or supermarket elbow or pronatio dolorosa infantum or annular ligament displacement).tw. (42) 
108 or $9(3432)$

11 exp Child/ or exp Infant/ or exp Pediatrics/ or Adolescent/ (3173635)

12 (child $^{\star}$ or infant ${ }^{\star}$ or pediatric ${ }^{\star}$ or paediatric ${ }^{\star}$ or toddler ${ }^{\star}$ or adolescent ${ }^{\star}$ ).tw. (1620321)

1311 or $12(3538238)$

1410 and 13 (1654)

15 Randomized controlled trial.pt. (429552)

16 Controlled clinical trial.pt. (91634)

17 randomized.ab. (368786)

18 placebo.ab. (178430)

19 Drug therapy.fs. (1902478)

20 randomly.ab. (262645)

21 trial.ab. (383644)

22 groups.ab. (1634679)

23 or/15-22 (3891094)

24 exp Animals/ not Humans/ (4306043)

2523 not 24 (3356638)

2614 and 25 (92)

$27\left(201110^{\star}\right.$ or $201111^{\star}$ or $201112^{\star}$ or $2012^{\star}$ or $2013^{\star}$ or $2014^{\star}$ or $2015^{\star}$ or $\left.2016^{\star}\right)$.ed,dc. $(6001473)$

2826 and 27 (24)

\section{Embase (Ovid Online)}

1 Elbow Dislocation/ (1134)

2 Elbow/ or Elbow Injury/ (17234)

3 elbow.tw. (29252)

4 ((radial or radius) and (head or distal)).tw. (18996)

52 or 3 or 4 (50919)

6 Dislocation/ or Subluxation/ (15569)

7 (dislocate* or slipped or pulled or sublux ${ }^{*}$ or internal derangement or painful pronation or internally deranged).tw. (26084)

86 or 7 (37869)

95 and 8 (2331)

101 or 9 (3289)

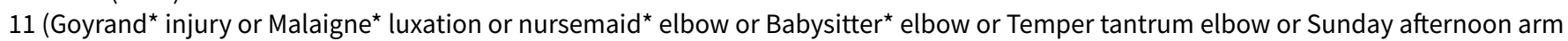
or Gromeyer* injury or curbstone fracture or supermarket elbow or pronatio dolorosa infantum or annular ligament displacement).tw. (49)

1210 or 11 (3301)

13 exp Child/ or Pediatrics/ or Adolescent/ (2971604)

14 (child $^{\star}$ or infant ${ }^{\star}$ or pediatric ${ }^{\star}$ or paediatric ${ }^{\star}$ or toddler ${ }^{\star}$ or adolescent $\left.^{\star}\right)$.tw. (1895817)

1513 or 14 (3467151)

1612 and 15 (1295)

17 Randomized controlled trial/ (416151)

18 Clinical trial/ (866278)

19 Controlled clinical trial/ (397539)

20 Randomization/ (71772)

21 Single blind procedure/ (22979)

22 Double blind procedure/ (131292)

23 Crossover procedure/ (48506)

24 Placebo/ (280258)

25 Prospective Study/ (349547)

26 ((clinical or controlled or comparative or placebo or prospective\$ or randomi\#ed) adj3 (trial or study)).tw. (941011)

27 (random* adj7 (allocat ${ }^{\star}$ or allot* or assign $^{\star}$ or basis* or divid $^{\star}$ or order $\left.{ }^{\star}\right)$ ).tw. (232779)

$28\left(\left(\right.\right.$ singl ${ }^{\star}$ or doubl ${ }^{\star}$ or trebl* or tripl $\left.{ }^{\star}\right)$ adj7 (blind ${ }^{\star}$ or mask $\left.\left.^{\star}\right)\right)$.tw. (188971)

29 (cross? over ${ }^{\star}$ or (cross adj1 over $\left.{ }^{\star}\right)$ ).tw. (81782)

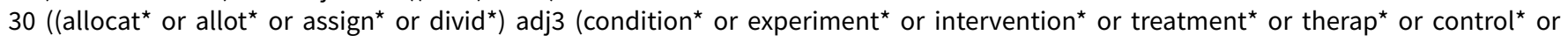
group $\left.)^{\star}\right)$.tw. (310004)

31 RCT.tw. (21407)

32 or/17-31 (2259319)

33 Case Study/ or Abstract Report/ or Letter/ (1011357)

3432 not 33 (2216645)

3516 and $34(86)$

$36\left(2011^{\star}\right.$ or $2012^{\star}$ or $2013^{\star}$ or $2014^{\star}$ or $2015^{\star}$ or $\left.2016^{\star}\right)$.em,dd. (8903742)

3735 and $36(30)$ 


\section{CINAHL (EBSCO)}

S1 (MH "Elbow Dislocation") (131)

S2 (MH "Elbow") OR (MH "Elbow Joint") (3,417)

S3 TX ( radial or radius ) or TX ( head or distal ) $(116,800)$

S4 S2 or S3 $(119,543)$

S5 TX dislocate* or slipped or pulled or sublux* or "internal derangement" or "painful pronation" or "internally deranged" (5,464)

S6 S4 and S5 (846)

S7 TX "Goyrand's injury" or "Malaigne's luxation" or "nursemaid's elbow" or "Babysitter's elbow" or "Temper tantrum elbow" or "Sunday afternoon arm" or "Gromeyer's injury" or "curbstone fracture" or "supermarket elbow" or "pronatio dolorosa infantum" or "annular ligament displacement" (22)

S8 S1 or S6 or S7 (977)

S9 (MH "Child") (321,571)

S10 (MH "Infant") (121,054)

S11 (MH "Pediatrics") $(13,431)$

S12 (MH "Adolescence") $(360,897)$

S13 TX child* OR infant* OR pediatric ${ }^{\star}$ OR paediatric ${ }^{\star}$ OR toddler ${ }^{\star}$ OR adolescent* $(934,476)$

$\mathrm{S} 14 \mathrm{~S} 9$ or $\mathrm{S} 10$ or $\mathrm{S} 11$ or $\mathrm{S} 12$ or S13 $(934,489)$

S15 S8 and S14 (448)

S16 (MH "Clinical Trials+") $(202,246)$

S17 (MH "Evaluation Research+") $(29,704)$

S18 (MH "Comparative Studies") $(91,730)$

S19 (MH "Crossover Design") (13,919)

S20 PT Clinical Trial $(79,712)$

S21 (MH "Random Assignment") (41,528)

S22 S16 or S17 or S18 or S19 or S20 or S21 $(319,977)$

S23 TX ((clinical or controlled or comparative or placebo or prospective or randomi?ed) and (trial or study)) $(925,857)$

S24 TX (random* and (allocat* or allot* or assign* or basis* or divid ${ }^{\star}$ or order $\left.\left.^{\star}\right)\right)(83,103)$

S25 TX ((singl ${ }^{\star}$ or doubl ${ }^{\star}$ or trebl ${ }^{\star}$ or tripl* $l^{\star}$ and $\left(\right.$ blind $^{\star}$ or mask $\left.\left.^{\star}\right)\right)(870,042)$

S26 TX ( crossover* or 'cross over' ) or TX cross n1 over $(18,248)$

S27 TX ((allocat ${ }^{\star}$ or allot ${ }^{\star}$ or assign ${ }^{\star}$ or divid ${ }^{\star}$ ) and (condition ${ }^{\star}$ or experiment ${ }^{\star}$ or intervention ${ }^{\star}$ or treatment ${ }^{\star}$ or therap $^{\star}$ or control $^{\star}$ or group $\left.\left.^{\star}\right)\right)(109,735)$

S28 S23 or S24 or S25 or S26 or S27 $(1,635,889)$

S29 S22 or S28 $(1,645,773)$

S30 S15 and S29 (239)

S31 EM 2011 OR EM 2012 OR EM 2013 OR EM 2014 OR EM 2015 OR EM $2016(2,007,802)$

S32 S30 AND S31 (91)

\section{LILACS}

((Mh Elbow Joint or Mh Elbow or Tw elbow or ((Tw radial or Tw radius) and (Tw head or Tw distal))) and (Mh Dislocations or Tw dislocate\$ or Tw slipped or Tw pulled or Tw sublux\$ or Tw internal derangement or Tw painful pronation or Tw internally deranged)) or (Tw Goyrand's injury or Tw Malaigne's luxation or Tw nursemaid's elbow or Tw Babysitter's elbow or Tw Temper tantrum elbow or Tw Sunday afternoon arm or Tw Gromeyer's injury or Tw curbstone fracture or Tw supermarket elbow or Tw pronatio dolorosa infantum or Tw annular ligament displacement) or ((Mh Codo or Tw Codo or Mh Articulação do Cotovelo) and (Tw dislocaci\$ OR Tw subluxaci\$)) or ((Mh Cotovelo or tw Cotovelo or Mh Articulação do Cotovelo) and (Tw disloca\$ or Tw subluxaç\$))[Palavras]

And

(Mh Child or Mh Infant or Mh Pediatrics or Mh Adolescent or Tw child\$ or Tw infant\$ or Tw pediatric\$ or Tw paediatric\$ or Tw toddler\$ or Tw adolescent\$) [Palavras]

And

((Pt Randomized controlled trial or Pt Controlled clinical trial or Mh Randomized controlled trials or Mh random allocation or Mh doubleblind method or Mh single-blind method or Pt Multicenter study) or ((Tw ensaio or Tw ensayo or Tw trial) and (Tw azar or Tw acaso or Tw placebo or Tw control\$ or Tw aleat\$ or Tw random\$ or (Tw duplo and Tw cego) or (Tw doble and Tw ciego) or (Tw double and Tw blind)) and Tw clinic\$)) and not ((Ct animals or Mh animals or Ct rabbits or Ct mice or Mh rats or Mh primates or Mh dogs or Mh rabbits or Mh swine) and not (Ct human and Ct animals)) [Palavras]

Total $=0$

\section{PEDro}

\section{Advanced search}


Abstract \& Title: Dislocate/slipped/ pulled/ sublux/ internal derangement/ painful pronation/ïnternally deranged/ Body part: forearm or elbow

Method: clinical trial

New records added since: 01/07/2011

Total $=0$

Simple search

1. Radial head (12)

2. Pulled elbow (2)

\section{ISRCTN Registry}

1. elbow and pulled (2)

2. elbow and dislocate ${ }^{\star}(0)$

3. elbow and sublux* $(0)$

4. elbow and pronation (2)

5. radial and head and pulled $(0)$

6. radial and head and sublux ${ }^{\star}(0)$

7. radial and head and dislocat ${ }^{\star}(0)$

\section{WHO ICTRP}

1. Elbow AND dislocate* OR Elbow AND slipped OR Elbow AND pulled OR Elbow AND sublux* OR Elbow AND derange* OR Elbow AND pronation (8)

2. Radial AND head AND dislocate* OR Radial AND head AND slipped OR Radial AND head AND pulled OR Radial AND head AND sublux ${ }^{\star}$ OR Radial AND head AND derange* OR Radial AND head AND pronation (1)

\section{ClinicalTrials.gov}

1. elbow AND (dislocate OR slipped OR pulled OR subluxation OR derangement OR pronation OR deranged) (30)

2. radial AND head AND (dislocate OR slipped OR pulled OR subluxation OR derangement OR pronation OR deranged) (3)

\section{Appendix 2. Reports of search results in previous versions of the review}

\section{First version: 2009, Issue 4 (Date of search: January 2009)}

The numbers of records identified via our searches of individual databases for the first version of the review were as follows: Cochrane Central Register of Controlled Trials (19 records), PubMed (21 records), EMBASE (57 records), CINAHL (15 records), LILACS (no records) and PEDro (no records). After removing duplicates and screening of titles and abstracts, together with references provided from the Specialised Register of the Cochrane Bone, Joint and Muscle Trauma Group, we identified five potentially eligible studies. Of these, four were published in full and one was a conference abstract. Upon study selection, three studies (Green 2006; Macias 1998; McDonald 1999) were included, one was excluded (Taha 2000) and one, only reported as a conference abstract, awaited classification (Vidosavljevic 2006).

\section{Second version: 2012, Issue 1 (Date of search: July 2011)}

For this update (July 2011), we screened a total of 68 records from the following databases: Specialised Register of the Cochrane Bone, Joint and Muscle Trauma Group (one record), Cochrane Central Register of Controlled Trials (21 records), MEDLINE (five records), EMBASE (seven records), CINAHL (31 records), LILACS (no records), PEDro (two records) and The WHO International Clinical Trials Registry Platform (one record). The results from the previous searches (up to January 2009) are shown in Appendix 2.

The search update resulted in the identification of two potentially eligible studies. Upon study selection, one was included (Bek 2009) and the other placed in 'Ongoing studies' (NCT00993954).

Overall, there are now four included trials (Bek 2009; Green 2006; Macias 1998; McDonald 1999), one excluded study (Taha 2000), one ongoing trial (NCT00993954), and one study, which was only reported as a conference abstract, continued to await classification (Vidosavljevic 2006)

\section{WHAT'S NEW}




\begin{tabular}{lll}
\hline Date & Event & Description \\
\hline 27 July 2017 & New search has been performed & $\begin{array}{l}\text { 1. The search was updated to September 2016 and five new stud- } \\
\text { ies identified and included (Asadi 2011; Garcia-Mata 2014; Gu- } \\
\text { naydin 2013; Guzel 2014; Schunk 1990). }\end{array}$ \\
& $\begin{array}{l}\text { 2. An extra comparison was added: supination-extension versus } \\
\text { supination-flexion. } \\
\text { 3. We used GRADE to assess the quality of evidence and pro- } \\
\text { duced a 'Summary of findings' table. }\end{array}$ \\
& $\begin{array}{l}\text { 4. There were changes to the byline. } \\
27 \text { July } 2017\end{array}$ & $\begin{array}{l}\text { New citation required and conclusions conclusions were moderated as a consequence of the in- } \\
\text { clusion of new evidence and assessment of this using GRADE. }\end{array}$ \\
\hline
\end{tabular}

\section{HISTORY}

Protocol first published: Issue 2, 2009

Review first published: Issue 4, 2009

\begin{tabular}{lll}
\hline Date & Event & Description \\
\hline 2 December 2011 & $\begin{array}{l}\text { New citation required but conclusions } \\
\text { have not changed }\end{array}$ & The conclusions were unchanged. \\
\hline 2 December 2011 & New search has been performed & $\begin{array}{l}\text { For this first update of the review, the following changes were } \\
\text { made: } \\
\text { 1. The search was updated to July 2011. } \\
\text { 2. One new trial (Bek 2009) was included and one ongoing trial } \\
\text { (NCT00993954) was added to 'Ongoing studies'. }\end{array}$ \\
\hline
\end{tabular}

\section{CONTRIBUTIONS OF AUTHORS}

\section{Marjolein Krul}

Drafting the protocol; searching the literature; inclusion procedure; data extraction and assessing risk of bias; drafting the text of the first published version of the review.

\section{Johannes $\mathrm{C}$ van der Wouden}

Contact author: providing general advice on the protocol and review; methodological advice; inclusion procedure; data extraction and assessing risk of bias. Drafting the text of the 2017 update.

\section{Emma J Kruithof}

Inclusion, data extraction and risk of bias assessment for the 2017 update. Interpreted results and assisted in drafting text.

\section{Lisette WA van Suijlekom-Smit}

Providing general advice on the protocol and review.

\section{Bart W Koes}

Providing general advice on the protocol and review.

\section{DECLARATIONS OF INTEREST}

None known. 


\section{SOURCES OF SUPPORT}

\section{Internal sources}

- Department of General Practice, Erasmus MC, Netherlands.

- Department of General Practice and Elderly Care Medicine, Amsterdam Public Health research institute, VUmc University Medical Center Amsterdam, Netherlands.

\section{External sources}

- No sources of support supplied

\section{DIFFERENCES BETWEEN PROTOCOL AND REVIEW}

We had not anticipated that attempts for reducing the pulled elbow could have been made before the child entered into the study. We found one study where this was reported to be the case in $15 \%$ of the participants, a study performed in a tertiary paediatric orthopaedic unit (Garcia-Mata 2014). We decided to include all children in the analysis, and perform a sensitivity analysis without the inclusion of the data from the $15 \%$.

We added continued failure after a second attempt using the same initial procedure as an additional secondary outcome.

We also used Google to search for studies (October 2016) and found one study from Iran which was included for this update (Asadi 2011).

\section{INDEX TERMS}

\section{Medical Subject Headings (MeSH)}

${ }^{\star}$ Elbow Injuries; Joint Dislocations [etiology] [^therapy]; Manipulation, Orthopedic [adverse effects] [*methods] [statistics \& numerical data]; Pain Measurement; Pronation; Radius [ ${ }^{*}$ injuries]; Randomized Controlled Trials as Topic; Sprains and Strains [etiology] [^therapy]; Supination; Treatment Failure

\section{MeSH check words}

Child, Preschool; Female; Humans; Infant; Male 